\title{
An embedded FE model for modelling reinforced concrete slabs in fire
}

\author{
Xinmeng $\mathrm{Yu}^{*}$ and Zhaohui Huang \\ Department of Civil and Structural Engineering, University of Sheffield, Sheffield S1 3JD, UK
}

\begin{abstract}
It is evident from a series of tests on simply supported reinforced concrete slabs that the failure of the slabs at large deflections is due to the formation of individual large cracks. This failure mode was also observed in the Cardington full-scale fire tests. Previous research indicates that the global behaviour of concrete slabs subject to large deflections can be well predicted by the smeared cracking model; however, the model cannot quantitatively predict the openings of individual cracks within the slabs at large deflection. For the discrete approach it is usually assumed that the cracks are formed along element edges, therefore continuous re-meshing is required during the analysis. Consequently, the results are mesh-dependent and the computing cost is high. In recent years, mesh independent finite element procedures, such as embedded (EFEM) and extended (XFEM) approaches, were widely used for modelling of the crack initiation and growth in structural members. However, most of the meshless models developed are either based on in-plane loading conditions or confined to thin shells with assumed full-depth cracks, which form apparent displacement jumps within an element.
\end{abstract}

For a reinforced concrete slab, out-of -plane load causes coupled stretching and bending of the slab, cracks are usually initiated at discrete positions and then propagated, until at last some individual full-depth cracks are formed. Pure stretching or assumed full-depth cracking is inadequate for modelling this kind of failure. Therefore, in this research, a non-linear layered procedure with embedded weak discontinuity is developed to quantitatively model the progressive tensile failure of reinforced concrete slabs subjected to large deflections. The current model inherits the advantage of smeared approach, and at the same time, introduces the opening width of crack explicitly by taking the advantage of the better description of the kinematic characteristics of EFEM approach. A series of validations have been conducted against test data at both ambient and elevated temperatures, and

\footnotetext{
* Corresponding author: Tel: +44 114222 5362; Fax: +44 1142225700
}

E-mail address: x.m.yu@sheffield.ac.uk 
the research shows that the model developed in this paper is not sensitive to the FE mesh size and the aspect ratio of the slab. The results predicted by the model developed agreed well with the test data in terms of deflection and crack open width, and also agreed well with those modelled by the smeared model. Hence, this new approach provides a numerical method to predict the load capacity as well as to identify the occurrence and severity of crack failure in reinforced concrete slabs subjected to extreme loading conditions, such as fire.

Keywords: Reinforced concrete slab; Tensile failure; Embedded FEM; Weak discontinuity; Numerical modelling; Fire condition; Layered slab FE model. 


\title{
An embedded FE model for modelling reinforced concrete slabs in fire
}

\author{
Xinmeng Yu and Zhaohui Huang
}

\section{INTRODUCTION}

Previous research indicates that under fire conditions the survivability of a composite structure largely depends on the performance of concrete floor slabs, which are key structural components. This critical structural member is expected to undergo large deformation, far beyond the design load given by yield line theory. This is due to the development of secondary load carrying mechanisms, such as membrane action, after conventional strength limits have been reached.

Recently a series of small-scale reinforced concrete slabs were tested at elevated temperatures at the University of Manchester [1] and University of Sheffield [2]. The test slabs were uniform loaded with four edges simply supported. The maximum temperature of $900^{\circ} \mathrm{C}$ was reached in the test slabs [1]. It is evident that the failure of the slabs at large deflections is due to individual large cracks formed within the slabs. All tests showed that membrane action occurs, with compressive membrane stress occurring around the perimeter and tensile membrane stress occurring in the middle of the slab. The observed failure mode of all the slabs consisted of the formation of individual large cracks [1]. This failure mode of concrete floor slabs subject to large deflections was also observed in Cardington full-scale fire tests [3].

In the past decade, a significant amount of research has been conducted into the numerical modelling of structural behaviour of reinforced concrete slabs under fire conditions [4-9]. These models are all based on the continuous failure approach in which the smeared cracking method was adopted for modelling of concrete failure. It is evident that the models can simulate global behaviour of concrete slabs subject to large deflection with good accuracy. However, this approach cannot quantitatively predict the opening of individual cracks within the slabs. As discussed above, it is clear that when a big crack is formed in the concrete floor the criterion of structural integrity is violated, but the stability of structures may still be maintained. Recently Izzuddin and Elghazouli $[10,11]$ developed a numerical procedure for the non-linear analysis of axially restrained lightly reinforced concrete beams under both ambient and fire conditions. This model is based on the assumption of a single crack at mid-span, with a particular emphasis on failure assessment in 
respect of the rupture of steel reinforcement. Also the influence of bond-slip between reinforcing steel and concrete on the overall member response (leading to the ultimate failure state) is considered in the model. However, the model is still primarily focused on the structural load capacity of concrete members in fire. Hence, it is important to develop a numerical procedure in which both structural stability and integrity of the floor slabs can be assessed.

Traditionally a discrete cracking model can be used successfully for modelling of the formation and propagation of cracks within the structural members when the crack path is known in advance, either from experimental evidence, or because of the material composition of the structure (such as in laminated composites). In these cases, the finite element mesh can be constructed such that the crack path coincides with the element boundaries. Such a cohesive crack can be modelled by inserting interface elements between the continuum elements along the potential crack path. To allow for a more arbitrary direction of crack propagation, interface elements can be inserted between all continuum elements or a re-meshing procedure could be used to accommodate crack propagation. However, this approach suffers from a certain mesh bias, since the direction of crack propagation is not entirely free, but restricted to inter-element boundaries. The computing cost is also very high.

In recent years, there has been great interest in the development of mesh-independent (or meshless), finite element procedures for the modelling of crack initiation and growth in structural members. This is done by enriching a standard Finite Element Method (FEM) with extra degrees of freedom (DoF) without violating the fundamentals of continua FEM theory. These models use either the Embedded Finite Element Method (EFEM) or extended Finite Element Method (XFEM). The EFEM is based on Assumed Enhanced Strain (AES). The enrichment is usually the amplitude of the opening of the crack, and the assumed traction continuity condition across the discontinuities ensures that the enrichment can be condensed out at element level, so the application of this method into normal FEM is straight forward. EFEM provides a better kinematic description for discontinuous displacement fields than the pure continuum models in which the displacement jump is smeared uniformly over the entire element. However, this method still has some limitations, such as the stress/strain on both sides cannot be evaluated accurately when they are split by discontinuity [12]. For XFEM approach, the enhancement is based on the Partition of Unity (PU) concept, which defines the percentage contribution from the node to a particular position [13]. The approximation 
and enrichment functions are node-based, so the extra DoF cannot be eliminated at element level. The localized modes are then collected from the extra DoF at nodes according to the approximation functions applied. In XFEM, the strains/stresses on both sides of a stress-free crack are fully decoupled, thus superior kinematic properties can be better captured than EFEM [12]. However, at present the main applications of XFEM approach are limited in either in-plane behaviour of structural members (achieved by very fine mesh with high computing cost), or confined to thin shells with assumed full-depth discontinuities within an element [13-15] based on regularized displacement discontinuity.

Normally, reinforced concrete slabs are subjected to out-of plane loading conditions, therefore the deformations of the slabs are coupled with stretching in-plane and bending out-plane. The cracks within the slabs are usually initiated at discrete positions and then propagated. The main object of this paper is to develop a non-liner layered procedure in which the opening of the cracks within the floor slabs can be quantatively identified and, at the same time, the large deflections also can be well predicted. Therefore, the layered procedure developed previously by Huang et al [4] is enhanced with embedded weak discontinuity in which the strain is assumed to be discontinuous in cracked layers, but the displacement of the element is still assumed to be continuous. In this model the opening width of the cracks and the deformation of the integrated solid portion can be explicitly expressed. This development inherits the advantage of smeared approach, and at the same time introduces the opening width of crack explicitly by taking the advantage of the better description of kinematic characteristics of EFEM approach.

Concrete, as a quasi-brittle material, is inhomogeneous and anisotropic. In most circumstance, the crack path meanders through the cement paste and the aggregate mixture. The fracture zone of concrete is always characterised by micro-cracks. Hence, directly applying fracture mechanics theories based on homogeneous materials for modelling concrete cracking is not easy task. It would be better to describe this fracture by crack band [16], or fracture process zone (FPZ). Depending on the scale of observation or application, quasi-brittle materials, including concrete, fibre composites, mortar, etc., the FPZ can be enormously varied. As a compromise between reality and simplicity, quasi-brittle fracture may be described by the cohesive crack model. The FPZ at the crack front is modelled as a fictitious line crack transmitting cohesive (crack-bridging) stresses [17]. The aim of the work given in this paper, as the first phase of research on the modelling of integrity failure of 
floor slabs, is not to address the localized stress intensity mechanics, but to quantitatively identify the opening width of the cracks within the slabs without forfeiting the capability of predicting the global behaviour of reinforced concrete slabs subjected to out-of-plane load.

\section{NON-LINEAR LAYERED PROCEDURE WITH EMBEDDED WEAK DISCONTINUITIES}

\subsection{Previous layered slab element model}

A non-linear layered procedure has been developed at the University of Sheffield for the modelling of reinforced concrete slabs under fire conditions [4]. In this model, concrete slabs were modelled as an assemblage of finite plate elements. The elements used were the quadrilateral 9-noded higher-order isoparametric elements described by Bathe [18]. The plate elements were sub-divided into several layers representing concrete and distributed reinforcing steel as shown in Fig. 1. The main assumptions of the layered approach can be summarised as follows [4]:

- The slab elements are considered to be composed of plain concrete layers and reinforcing steel layers, as shown in Fig. 1, and there is no slip between layers.

- Each layer can have a different but uniform temperature. The initial material properties of each layer may be different, and the stress-strain relationships may change independently for each layer.

- The reinforcing steel bars in either of the orthogonal mesh directions are modelled by an equivalent, smeared, steel layer with stiffness only in the direction of the reinforcement. The thickness of the steel layer can be set so that the cross-sectional area of this layer is equal to the total area of its reinforcing bars. There can be multiple reinforcing layers in each longitudinal and transverse direction. Perfect bond is assumed between the reinforcing steel layers and the surrounding concrete.

- Concrete layers are in a state of plane stress, and concrete is considered to be orthotropic after cracking.

In this model smeared cracking method was adopted for modelling of concrete failure and both material and geometric non-linearities were taken into account. 


\subsection{Additional assumptions for the current model}

It is obvious that once one or more cracks are formed within the element, the basis of the FE formula in the continua is violated. In order to enrich the layered procedure developed by Huang et al. [4] with weak discontinuities some further assumptions are made as follows:

- After concrete cracking in each layer the crack discontinuity is enhanced by two orthogonal in-plane crack openings as extra degrees of freedom.

- A biaxial failure envelope is used to identify the initiation of crack. Once a crack is initiated in a certain layer the directions of principal stresses and strains in that layer are fixed by the crack orientation. It is also assumed that the crack propagates from the initiating point to adjacent layers with the same crack orientation.

- A uniform cohesive cracking interface is assumed, which is governed by linear or bilinear traction-displacement softening curves.

- In order to represent the influence caused by the stress variation in high-order elements, each of the orthogonal openings is decomposed onto integration points as virtual independent sub-cracks with the same orientation and length, determined by the first initiation of crack [see Fig. 2]. The magnitude of each sub-crack is governed by the corresponding stress and strain status at each corresponding integration point. The total opening width of each layer in the element is then approximately determined by summation from all integrating points.

- The total strain $(\varepsilon)$ in the direction normal to the crack is decomposed into continuous $(\tilde{\varepsilon})$ and discontinuous strains $(\hat{\varepsilon})$. The continuous strain associates with the deformation of the continuous (un-cracked) element. The discontinuous strain describes the relative motion between two sides of the crack interface. This is a general technique of EFEM. The standard FEM is applied for the continuous strain and the discontinuous strain is transformed from the crack opening width $(e)$ by means of scalable effective length of the element $\left(l_{\text {eff }}\right)$, which is the projection of the element on the normal to the crack direction $[16,19]$. That is,

$$
\begin{aligned}
& \varepsilon=\widetilde{\varepsilon}+\hat{\varepsilon} \\
& \hat{\varepsilon}=\gamma e / l_{e f f}
\end{aligned}
$$


where, $\gamma$ is the scale factor of the effective length and equal to the total number of integration points within the element. The usage of $\gamma$ extends the element effective size concept from constant strain linear element to high order element, which can be assumed to be an assemblage of constant strain patches. Thus, coarser FE mesh can be used.

The coupling between the continuous solid and the discontinuous interface is enforced by means of the traction continuity condition across the crack interface. This provides an extra equation to condense the extra $\operatorname{DoF}(e)$ out from the stiffness matrix at element level. This condition can be expressed as

$$
\left\{\begin{array}{l}
\sigma=E \widetilde{\varepsilon} \\
t=f_{t}+D_{n n} e \\
\sigma=t
\end{array}\right.
$$

where $t=f_{t}+D_{n n} e$ is a general expression of the surface traction along the cohesive crack by assuming a linear or bi-linear stress-displacement softening curve (further explanation is given in Section 2.3.5), $f_{t}$ is the tensile strength of concrete, $D_{n n}$ is the slope of the softening curve, and $E$ is Young's modulus. Substituting Eqns. (1) and (2) into (3), the opening width, $e$ is obtained as

$$
e=\frac{E \varepsilon-f_{t}}{D_{n n}+\gamma E / l_{e f f}}
$$

\subsection{Development of the current model}

\subsubsection{Assumed Enhanced Strains (AES)}

Fig. 3 shows an element $(A B C D)$ with a crack band where $n$ is the normal to the crack interface direction, $O$ is the central point of the element. The effective length $l_{\text {eff }}^{n}$ is the size of the element transformed from $A B C D$ to abcd with equivalent area. According to Eqn. (2), the equivalent discontinuous strain is 


$$
\hat{\varepsilon}_{n}=\gamma e_{n} / l_{e f f}^{n}=\alpha_{n} e_{n}
$$

If the opening in $n$-direction does not exist or is closed, then $e_{n}=0$. Similarly, the equivalent discontinuous strain for the $s$-direction crack (if any) is

$$
\hat{\varepsilon}_{s}=\gamma e_{s} / l_{e f f}^{s}=\alpha_{s} e_{s}
$$

This can be expressed in compact matrix form as

$$
\hat{\boldsymbol{\varepsilon}}_{n}=\mathbf{M}_{e} \mathbf{e}
$$

where,

$$
\begin{aligned}
& \mathbf{M}_{e}=\left[\begin{array}{ccccc}
\alpha_{n} & 0 & 0 & 0 & 0 \\
0 & \alpha_{s} & 0 & 0 & 0
\end{array}\right]^{T} \\
& \hat{\boldsymbol{\varepsilon}}_{n}=\left\{\hat{\varepsilon}_{n} \hat{\varepsilon}_{s} 000\right\}^{T} \\
& \mathbf{e}=\left\{e_{n} e_{s}\right\}^{T}
\end{aligned}
$$

The extra zeroes in Eqns. (8) and (9) are used to make the enhanced strain and the continuous strain have the same number of components. So the matrix form of the continuous portion of strain in local $(n-s)$ coordinate system can be expressed as

$$
\widetilde{\boldsymbol{\varepsilon}}_{n}=\mathbf{T}_{\varepsilon} \boldsymbol{\varepsilon}-\mathbf{M}_{e} \mathbf{e}
$$

where $\varepsilon$ is the total Green-Lagrange strain at any point in the element and can be expressed as [4]:

$$
\boldsymbol{\varepsilon}=\left[\begin{array}{cc}
\mathbf{B}_{m} & z \mathbf{B}_{b}+\frac{1}{2} \mathbf{B}_{L}^{b} \\
0 & \mathbf{B}_{s}
\end{array}\right] \mathbf{d}=\mathbf{B}^{\varepsilon} \mathbf{d}
$$

in which $z$ is global coordinate; $\mathbf{B}_{m}, \mathbf{B}_{b}$ and $\mathbf{B}_{s}$ are generalized strain-displacement matrices 
related to linear small displacement, respectively; $\mathbf{B}_{L}^{b}$ is strain-displacement matrix related to large displacement; and $\mathbf{d}$ is total displacement vector. The details of $\mathbf{B}_{m}, \mathbf{B}_{b}, \mathbf{B}_{s}$ and $\mathbf{B}_{L}^{b}$ can be found in Reference [4].

$\mathbf{T}_{\varepsilon}$ is the strain transformation matrix from global $(x-y)$ to local $(n-s)$ coordinates. Therefore, the continuous strain in global $(x-y)$ coordinate system can be represented as

$$
\widetilde{\boldsymbol{\varepsilon}}_{x}=\mathbf{T}_{\varepsilon}^{-1}\left(\mathbf{T}_{\varepsilon} \boldsymbol{\varepsilon}-\mathbf{M}_{e} \mathbf{e}\right)=\boldsymbol{\varepsilon}-\mathbf{T}_{\varepsilon}^{-1} \mathbf{M}_{e} \mathbf{e}
$$

\subsubsection{Force equilibrium across the crack interface}

In Section 2.2, the extra degrees of freedom, e, is introduced as internal unknown parameters. Hence, extra equations are needed to solve these unknowns. The most natural requirement is that the traction vector across the crack should be equal to the stress tensor contracted with the crack normal at each integration point [19]. This traction continuity condition can be expressed as

$$
\mathbf{M}_{\sigma} \boldsymbol{\sigma}_{n}=\left\{f_{t}\right\}+\hat{\mathbf{D}} \mathbf{e}_{n}
$$

where, $\boldsymbol{\sigma}_{n}=\left\{\sigma_{n} \sigma_{s} \tau_{n s} \tau_{n t} \tau_{s t}\right\}^{T}$ is the stress vector in local $n-s$ directions, $\left\{f_{t}\right\}=\left\{f_{t}^{n} f_{t}^{s}\right\}^{T}$ is the tensile strength vector of concrete, $\hat{\mathbf{D}}$ is the reference stiffness of the cohesive crack interface (see Section 2.3.5), and

$$
\mathbf{M}_{\sigma}=\left[\begin{array}{ccccc}
\beta_{n} & 0 & 0 & 0 & 0 \\
0 & \beta_{s} & 0 & 0 & 0
\end{array}\right]
$$

where $\beta_{n}$ and $\beta_{s}$ are 1 for opened crack and 0 for undamaged or closed interface in $n$ and $s$ directions, respectively.

Assuming $\mathbf{D}^{\prime}$ is the constitutive matrix of the continuous solid in local $(n-s)$ coordinates, hence Eqn. (14) becomes

$$
\mathbf{M}_{\sigma} \mathbf{D}^{\prime} \boldsymbol{\varepsilon}_{n}=\left\{f_{t}\right\}+\hat{\mathbf{D}} \mathbf{e}
$$


Substituting Eqns. (11) (12) into (16), that is

$$
\mathbf{M}_{\sigma} \mathbf{D}^{\prime}\left(\mathbf{T}_{\varepsilon} \mathbf{B}^{\varepsilon} \mathbf{d}-\mathbf{M}_{e} \mathbf{e}\right)=\left\{f_{t}\right\}+\hat{\mathbf{D}} \mathbf{e}
$$

Using a linear or bi-linear strain softening curves (see Section 2.3.5) so that the derivative of $\hat{\mathbf{D}}$ is zero. A simple rearrangement of the differentiation of Eqn. (17) leads to the relationship between the rate equation of crack separation $(\dot{\mathbf{e}})$ and the nodal displacements $(\dot{\mathbf{d}})$ as shown in Eqn (18). The derivation is given in the Appendix.

$$
\dot{\mathbf{e}}=\left(\hat{\mathbf{D}}+\mathbf{M}_{\sigma} \mathbf{D}^{\prime} \mathbf{M}_{e}\right)^{-1} \mathbf{M}_{\sigma} \mathbf{D}^{\prime} \mathbf{T}_{\varepsilon} \mathbf{B} \dot{\mathbf{d}}
$$

where,

$$
\mathbf{B}=\left[\begin{array}{cc}
\mathbf{B}_{m} & z \mathbf{B}_{b}+\mathbf{B}_{L}^{b} \\
0 & \mathbf{B}_{s}
\end{array}\right]
$$

\subsubsection{Element stiffness matrix consistent with AES and traction continuity condition}

Due to the fact that the crack interface is so shallow compared with the element dimension (the stress tends to zero with the increment of opening width) it is assumed that the external forces are all taken by the continuous portion of the element [19]. Thus, the internal nodal forces in the cracked element are evaluated from the standard relation

$$
\mathbf{f}_{\mathrm{int}}=\int_{V} \mathbf{B}^{T} \boldsymbol{\sigma} d V
$$

The tangent stiffness of an element with embedded discontinuity [19] can be constructed by expressing the separation rate in terms of displacement rate as shown in Eqn. (18) and substituting into the rate form of the basic equation, Eqn. (20).

This process leads to

$$
\dot{\mathbf{f}}_{\mathrm{int}}=\int_{V} \mathbf{B}^{T} \dot{\boldsymbol{\sigma}} d V+\int_{V} \dot{\mathbf{B}}^{T} \boldsymbol{\sigma} d V
$$

The second term on the right hand side of Eqn. (21) is [4] 


$$
\int_{V} \dot{\mathbf{B}}^{T} \boldsymbol{\sigma} d V=\mathbf{K}_{\sigma} \dot{\mathbf{d}}
$$

where, $\mathbf{K}_{\sigma}$ is geometric matrix.

Using Eqns. (12) (13) and (18) the first term on the right hand side of Eqn. (21) can be expressed as (the derivation is given in the Appendix)

$$
\int_{V} \mathbf{B}^{T} \dot{\boldsymbol{\sigma}} d V=\left(\int_{V} \mathbf{B}^{T} \mathbf{D}\left(\mathbf{I}-\mathbf{T}_{\varepsilon}^{-1} \mathbf{M}_{e}\left(\hat{\mathbf{D}}+\mathbf{M}_{\sigma} \mathbf{D}^{\prime} \mathbf{M}_{e}\right)^{-1} \mathbf{M}_{\sigma} \mathbf{D}^{\prime} \mathbf{T}_{\varepsilon}\right) \mathbf{B} d V\right) \dot{\mathbf{d}}
$$

or

$$
\int_{V} \mathbf{B}^{T} \dot{\boldsymbol{\sigma}} d V=\left(\int_{V} \mathbf{B}^{T} \mathbf{D}^{w} \mathbf{B} d V\right) \dot{\mathbf{d}}=\mathbf{K}^{w} \dot{\mathbf{d}}
$$

where,

$$
\begin{aligned}
& \mathbf{D}^{w}=\mathbf{D}\left(\mathbf{I}-\mathbf{T}_{\varepsilon}^{-1} \mathbf{M}_{e}\left(\hat{\mathbf{D}}+\mathbf{M}_{\sigma} \mathbf{D}^{\prime} \mathbf{M}_{e}\right)^{-1} \mathbf{M}_{\sigma} \mathbf{D}^{\prime} \mathbf{T}_{\varepsilon}\right) \\
& \mathbf{K}^{w}=\int_{V} \mathbf{B}^{T} \mathbf{D}^{w} \mathbf{B} d V
\end{aligned}
$$

where $\mathbf{D}$ is the continuous constitutive matrix in the global coordinate system, which can be transformed from the local constitutive matrix $\mathbf{D}^{\prime}$. It is assumed that the integral concrete is isotropic, homogeneous and linearly elastic [4]. A correction factor $k=6 / 5$ is used to consider the effects of the parabolic shear stress distribution in $z$ direction. From Eqns. (21) (22) and (24) the tangent stiffness matrix of the slab element with embedded discontinuities is obtained as

$$
\mathbf{K}_{T}=\mathbf{K}^{w}+\mathbf{K}_{\sigma}
$$

It is obvious that the stiffness matrix $\mathbf{D}^{w}$ should vary between $[\mathbf{0}]$ and $[\mathbf{D}]$. When the opening of the crack tends to traction free, $\hat{\mathbf{D}} \rightarrow \mathbf{0}$, then $\mathbf{D}^{w} \rightarrow \mathbf{0}$. In order to make sure $\mathbf{D}^{w} \leq \mathbf{D}, \mathbf{D}^{w}$ should be positive, which means $\hat{\mathbf{D}}+\mathbf{M}_{\sigma} \mathbf{D}^{\prime} \mathbf{M}_{e} \geq \mathbf{0}$. 


\subsubsection{Integration of the element tangent stiffness matrix and internal nodal force vector}

In this study Gauss Quadrature is employed to evaluate the stiffness matrix of slab elements. For the non-linear analysis of 9-noded element, 9 Gauss integration points are used, as recommended by Bathe [18]. Therefore, all stresses and strains, and the material constitutive matrices, correspond to Gauss integration points. Since the elements are divided into layers in the $z$-direction as illustrated in Fig 1, the integrations with respect to $z$ are replaced by summation of the integral over the layers.

Rewriting Eqn. (19) as

$$
\mathbf{B}=\left[\begin{array}{cc}
\mathbf{B}_{m} & \mathbf{B}_{L}^{b} \\
0 & \mathbf{B}_{s}
\end{array}\right]+z\left[\begin{array}{cc}
0 & \mathbf{B}_{b} \\
0 & 0
\end{array}\right]=\mathbf{M}_{1}+z \mathbf{M}_{2}
$$

Substituting Eqn. (28) into Eqn. (26), as follows

$$
\begin{aligned}
& \mathbf{K}^{w}=\int_{V}\left(\mathbf{M}_{1}+z \mathbf{M}_{2}\right)^{T} \mathbf{D}^{w}\left(\mathbf{M}_{1}+z \mathbf{M}_{2}\right) d V \\
& =\int_{V}[\underbrace{\mathbf{M}_{1}^{T} \mathbf{D}^{w} \mathbf{M}_{1}}_{\mathbf{A}_{1}}+z(\underbrace{\mathbf{M}_{1}^{T} \mathbf{D}^{w} \mathbf{M}_{2}+\mathbf{M}_{2}^{T} \mathbf{D}^{w} \mathbf{M}_{1}}_{\mathbf{A}_{2}})+z^{2} \underbrace{\mathbf{M}_{2}^{T} \mathbf{D}^{w} \mathbf{M}_{2}}_{\mathbf{A}_{3}}] d V \\
& =\sum_{i=1}^{p} \int_{A}\left(h_{1}^{i} \mathbf{A}_{1}^{i}+h_{2}^{i} \mathbf{A}_{2}^{i}+h_{3}^{i} \mathbf{A}_{3}^{i}\right) d A \\
& =\sum_{i=1}^{p} \sum_{j=1}^{q}\left[\text { weight }_{j} \times\left(h_{1}^{i} \mathbf{A}_{1}^{i j}+h_{2}^{i} \mathbf{A}_{2}^{i j}+h_{3}^{i} \mathbf{A}_{3}^{i j}\right) \times \operatorname{Det}|J|\right]
\end{aligned}
$$

where $p$ is the total number of layers, $q=9$ is the total number of integration points, and

$$
\left\{\begin{array}{l}
h_{1}^{i}=h_{t o p, i}-h_{b o t, i} \\
h_{2}^{i}=\frac{1}{2}\left(h_{t o p, i}^{2}-h_{b o t, i}^{2}\right) \\
h_{3}^{i}=\frac{1}{3}\left(h_{t o p, i}^{3}-h_{b o t, i}^{3}\right)
\end{array}\right.
$$

where $h_{t o p, i}$ and $h_{b o t, i}$ are the top and bottom coordinates of the $i$-th layer in $z$ direction. The detail of formation of $\mathbf{K}_{\sigma}$ can be found in Reference [4]. Hence, using Eqn. (27) element tangent stiffness matrix, $\mathbf{K}_{T}$, can be formed. 
The similar procedure can be used to calculate the internal nodal force vector, $\mathbf{f}_{\text {int }}$, as follows,

$$
\begin{aligned}
& \mathbf{f}_{\mathrm{int}}=\int_{V}(\underbrace{\left[\begin{array}{cc}
\mathbf{B}_{m} & \mathbf{B}_{L}^{b} \\
\mathbf{0} & k \mathbf{B}_{s}
\end{array}\right]}_{\mathbf{M}_{3}}+z\left[\begin{array}{cc}
\mathbf{0} & \mathbf{B}_{b} \\
\mathbf{0} & \mathbf{0}
\end{array}\right])^{T} \boldsymbol{\sigma} d V \\
& =\sum_{i=1}^{p}\left(h_{1}^{i} \int_{A} \mathbf{M}_{3, i}^{T} \boldsymbol{\sigma}_{i} d A+h_{2}^{i} \int_{A} \mathbf{M}_{2, i}^{T} \boldsymbol{\sigma}_{i} d A\right) \\
& =\sum_{i=1}^{p} \sum_{j=1}^{q}\left[\text { weight }_{j} \times\left(h_{1}^{i} \mathbf{M}_{3, i j}^{T} \boldsymbol{\sigma}_{i j}+h_{2}^{i} \mathbf{M}_{2, i j}^{T} \boldsymbol{\sigma}_{i j}\right) \times \operatorname{Det}|J|\right]
\end{aligned}
$$

where $k=5 / 6$ for considering the influence of the non-uniformity of the shearing stress [4].

\subsubsection{Constitutive relationship}

\subsubsection{The cohesive law}

In this research Mode I crack model is adopted for simplicity. The initiation of cracks is based on bi-axial concrete failure envelope [4]. After cracking, linear elastic material properties are assumed in the continuous solid, but linear or bi-linear softening curves (see Fig. 4) is assumed on the crack interface. Because of the orthotropic assumption after cracking, the principal stress and strain directions are assumed to be fixed with the crack orientation. The reference stiffness matrix $\hat{\mathbf{D}}$ is a $2 \times 2$ diagonal matrix, that is

$$
\hat{\mathbf{D}}=\left[\begin{array}{cc}
D_{n n} & 0 \\
0 & D_{s s}
\end{array}\right]
$$

where, $D_{n n}$ and $D_{s s}$ are the tangent stiffness of the orthogonal cohesive crack interfaces in $n$ and $s$ directions, respectively. Let $f(e, \kappa)=e-\kappa$ be the loading or unloading function, in which $\kappa$ is the maximum normal opening width attained. Then $f \geq 0$ indicates loading (growing damage) and $f<0$ indicates unloading (crack closing). For loading, $D_{n n}$ and $D_{s s}$ are derivatives of the softening function. For unloading, $D_{n n}$ and $D_{s s}$ are replaced by secant stiffness [20]. For 
assumed orthogonal cracks, the rate of traction $\left(\dot{t}_{n}, \dot{t}_{s}\right)$ across the cohesive crack interface can be calculated using

$$
\left\{\begin{array}{l}
\dot{t}_{n} \\
\dot{t}_{s}
\end{array}\right\}=\left[\begin{array}{cc}
D_{n n} & 0 \\
0 & D_{s s}
\end{array}\right]\left\{\begin{array}{l}
\dot{e}_{n} \\
\dot{e}_{s}
\end{array}\right\}
$$

where, $\dot{e}_{n}, \dot{e}_{s}$ are the rate form of cohesive crack openings.

If the opening exceeds the traction free open width (according to the softening curve) the tangent reference stiffness is set to zero. In this research, for simplicity, if cracks are closed in both of the directions then the undamaged material stiffness is regained.

\subsubsection{The fracture energy}

In the cohesive interface, the softening curve is governed by the fracture energy, which is a material property. In $C E B$-FIP model code [21], the fracture energy $\left(G_{F}\right.$, in $\left.\mathrm{N} / \mathrm{m}\right)$, which is based on work-of-fracture method, is a function of the compressive strength of concrete $\left(f_{c}\right.$, in positive MPa) and the maximum aggregate size ( $d_{a}$, in mm). Bazant et al. [22] proposed a new fracture energy formulation in which the water-cement ratio $(w / c)$ is also taken into account. The fracture energy is expressed as

$$
G_{F}=2.5 \times \alpha_{0}\left(\frac{f_{c}}{0.051}\right)^{0.46}\left(1+\frac{d_{a}}{11.27}\right)^{0.22}\left(\frac{w}{c}\right)^{-0.30}
$$

where $\alpha_{0}=1.0$ for rounded aggregates, and $\alpha_{0}=1.44$ for crushed or angular aggregates. This formulation is adopted in this research.

Because of the fracture in a reinforced concrete is somewhat different from in plain concrete. In cracked reinforced concrete structures, reinforcement imparts some load (stress) to the concrete between cracks via bond action so that this effectively leads to above-zero tensile stress existing in cracked concrete [23]. The mechanism, commonly known as tension stiffening, is usually assumed to be limited to a volume on concrete within 7.5 bar diameters from the reinforcement centre [21]. 
Therefore, in this research this mechanism is taken into account in a very simple way. That is, the fracture energy is arbitrary raised by $10 \%$ for concrete within the tension stiffening zone.

\subsubsection{Extension of the current model to elevated temperatures}

It is reasonable to keep the fracture energy constant during the numerical procedure at ambient temperature. However, the fracture energy of concrete changes at elevated temperatures. This should be considered in the model for fire conditions. In order to extend implementation of the model described above to elevated temperatures, the fracture energy is associated with temperature according to $C E B-F I P$ model code 1990 [21], that is

$$
G_{F}(T)=G_{F}^{T=20}(1.06-0.003 T)
$$

where, $T$ is the temperature in ${ }^{0} C$.

In addition to the fracture energy, the thermal strains of the materials $\left(\varepsilon_{T}\right)$ at elevated temperature are considered as another strain component, that is,

$$
\varepsilon=\widetilde{\varepsilon}+\hat{\varepsilon}+\varepsilon_{T}
$$

Because the thermal strain is constant in each step of numerical analysis, Eqn. (36) can be rewritten as

$$
\varepsilon-\varepsilon_{T}=\widetilde{\varepsilon}+\hat{\varepsilon}
$$

Therefore, the crack opening width at elevated temperatures can be obtained by a slight modification of the assumption in Eqn. (4) as

$$
e=\frac{E\left(\varepsilon-\varepsilon_{T}\right)-f_{t}}{D_{n n}+\gamma E / l_{e f f}}
$$

The numerical procedure presented above has now been incorporated into Vulcan to model the structural behaviour of reinforced concrete slabs in fire conditions. The Newton-Raphson iteration procedure is employed. The total loading or temperature rise for which the response of the structure 
is to be traced is divided into a number of steps. It is assumed that changes in the loads or temperatures occur only at the beginning or end of a step. During any step the external loads and temperatures in the layers of all elements are assumed to remain constant.

\section{VALIDATIONS}

In order to demonstrate the capability of the formulation described above to model reinforced concrete slabs under both ambient and fire conditions, total 7 two-way simply supported reinforced concrete slabs tested at the University of Manchester [1] and University of Sheffield [2] were modelled in this paper.

\subsection{Modelling of the slabs tested at ambient temperature}

The details of the four tested slabs [1] used here are listed in Table 1. All four slabs were loaded via an air bag so that uniform load distribution could be achieved. Two rectangular slabs (1.8m x 1.2m) and two square slabs $(1.2 \mathrm{~m} \times 1.2 \mathrm{~m})$ were modelled in this study. The tested material properties were used as input data for the modelling. The fracture energies were calculated according to Eqn. (34). The equivalent thickness of the reinforcement layers were calculated from real area of steel rebar used in the test specimens. In order to investigate the mesh sensitivity of the current model some of the slabs were also modelled using different meshes. The comparisons of the results predicted by the current model with different meshes and previous smear model [4], together with the test results are show in Figs. 5-8. It is evident that the predictions of the current model agreed well with test results and the predictions of the smear model [4]. Therefore, the current model can predict well the global behaviour of slabs in term of deflection. Also it can be seen that the current model is not mesh sensitive in term of deflection. It is obvious that steel reinforcement plays a very important roll in the load capacity of reinforced slabs subject to large deflection. In order to investigate the mesh sensitivity on the stress of the reinforcement, Fig. 10 shows the stresses of reinforcing steel at the integration point nearest to the centre of M1-Slab (Point 9 in Fig. 9) for different meshes. It can be seen from the figure that the reinforcement stresses generated by two meshes are almost the same. The small difference is due to the integration points of the two meshes not being at exactly the same position within the slab. However, the results present further strong evident to confirm that the current model is not mesh sensitive in terms of the stress as well. 
In order to examine the ability of the current model to predict the crack openings within the reinforced concrete slabs at large deflections, a detail analysis was carried out on the slab specimen M1. The M1 slab was modelled with 36 elements and each of the elements was sub-divided into 17 layers. During the analysis the cracks within the slab was progressing layer by layer from the initial crack position. The cracking pattern on the bottom and top surfaces of the M1 slab at the load of $20 \mathrm{kN} / \mathrm{m}^{2}$ is shown in Figs. 11 and 12, respectively. It is evident that the cracking on the bottom surface was along the yield line layout. The layout of the cracking along the thickness direction of the slab at the position of element\#15 (see Fig. 11) is shown in Fig. 13. It can be seen that the crack along the long span direction decreased from the bottom to top layers, and there was no crack (with zero open width) on the top later. However, a vertical crack formed along the short span direction in which the opening widths of bottom layer and top layer were $2.28 \mathrm{~mm}$ and $1.7 \mathrm{~mm}$, respectively. This can be confirmed by the test observation [1], in which only one large crack appeared in the short span on the top surface of the slab (see Fig. 14).

\subsection{Modelling of the slabs tested at elevated temperatures}

The details of the three test slabs $[1,2]$ used in this validation are listed in Table 2. All the slabs were uniformly loaded during the test. Linear temperature distribution between the top and bottom surfaces was assumed in the model. The layered temperatures were then calculated according to the measured surface temperature data. The tested material properties at ambient temperature were used in the modelling. Figs. 15-17 show the comparisons of the central deflections of the slabs predicted by the current model against test results, together with the predictions of previous smear model [4]. It can be seen that reasonable agreements between the current model's predictions, test results and smear model's predictions were achieved. This again confirms that current model can predict well the global behaviours of reinforced concrete slabs in fire.

The predicted cracking pattern of the test slab MF1 [1] is shown in Fig. 18. It is evident that a large through crack was formed along short span of the slab in which the opening width of the crack is about $62 \mathrm{~mm}$. The cracking pattern of Slab M1 observed in the test is shown in Fig. 19. It can be seen that the maximum crack opening along the short span was about $75 \mathrm{~mm}$. This comparison further validates the ability of the non-linear procedure proposed in this paper for modelling integrity failure of reinforced concrete slabs subjected to extreme loading conditions, such as fire. 


\section{CONCLUSIONS}

In this research, a new layered slab element model has been developed to model the structural behaviour of reinforced concrete slabs subject to large deflections. This model enhanced the previous non-linear layered procedure developed at the University of Sheffield [4] with embedded weak discontinuities in order to trace the crack openings in reinforced concrete slabs. In this approach, the total strain is decomposed into continuous and discontinuous strains. The continuous strain is associated with the deformation of integrated part of the elements and the discontinuous strain is converted from the opening width of the crack by means of the effective length of the element. The magnitude of the crack opening is modelled by extra degrees of freedom, which are governed by the traction continuity conditions across the uniform cohesive crack interface. In order to account for the stress variation in the element, the discontinuity is decomposed into virtual sub-cracks which are governed by the corresponding stress and strain states at each integration point. The validations show that the model can predict the global behaviour of slabs at both ambient and elevated temperatures with reasonable accuracy, and at the same time individual crack openings within the slabs can be identified. The predicted cracking pattern agreed well with the experiment results. Thus the current model provides an excellent numerical approach for assessing both structural stability and integrity of floor slabs under fire conditions. It is evident that this approach is not sensitive to mesh discretization and aspect-ratio of slabs.

It should be pointed out that in the current model the bond characteristics between steel mesh and concrete are not taken into account, and perfect bounding was assumed in the model. Hence, further research is needed to include the bond characteristic between concrete and reinforcing steel into the current model.

\section{ACKNOWLEDGEMENTS}

Thanks are due to the directors of our research group, Professors Ian Burgess, and Roger Plank. Help from Professor Harm Askes of the University of Sheffield is also gratefully acknowledged. 


\section{APPENDIX}

(1) Derivation of Eqn. (18) from Eqn. (17)

From Equation (12), let

$$
\mathbf{B}^{\varepsilon}=\mathbf{B}_{L}+\mathbf{B}_{N L}
$$

where

$$
\mathbf{B}_{L}=\left[\begin{array}{cc}
\mathbf{B}_{m} & z \mathbf{B}_{b} \\
\mathbf{0} & \mathbf{B}_{s}
\end{array}\right]
$$

and

$$
\mathbf{B}_{N L}=\left[\begin{array}{cc}
\mathbf{0} & \frac{1}{2} \mathbf{B}_{L}^{b} \\
\mathbf{0} & \mathbf{0}
\end{array}\right]
$$

$\mathbf{B}_{L}$ is the linear-small-displacement strain-displacement relationship matrix; $\mathbf{B}_{N L}$ is the non-linear large-displacement strain-displacement relationship matrix. For the former, its derivative is zero, for the latter, because of the special form of the $\mathbf{B}_{L}^{b}$ [4] as shown in Eqns. (A4) and (A5),

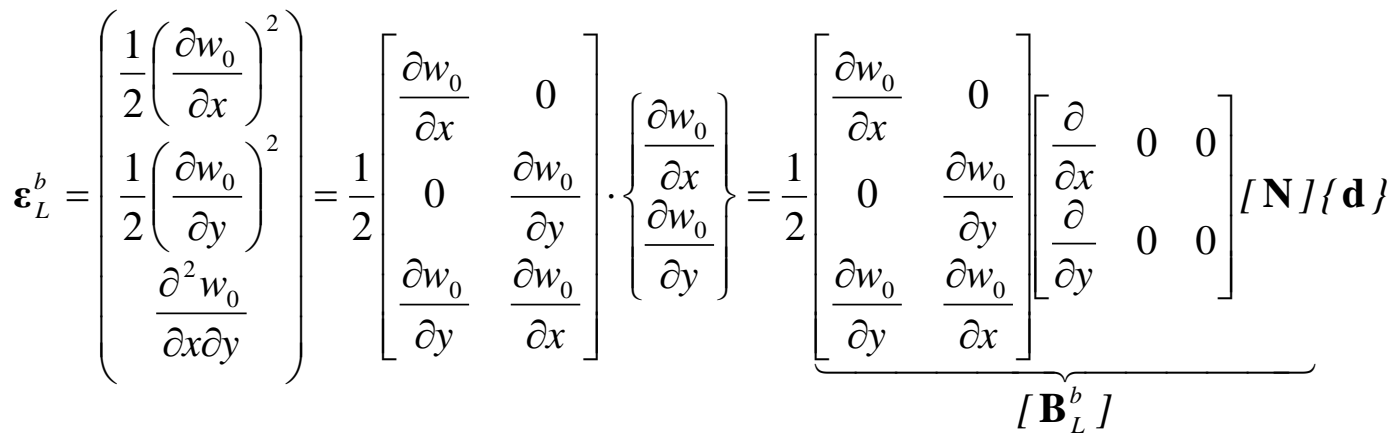

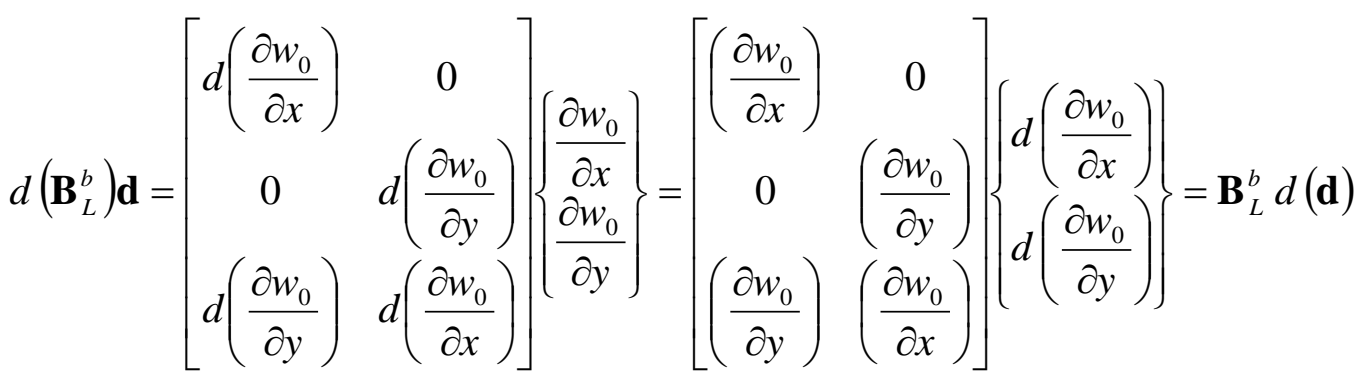


hence,

$$
d\left(\mathbf{B}^{\varepsilon} \mathbf{d}\right)=d\left(\mathbf{B}_{L} \mathbf{d}\right)+d\left(\mathbf{B}_{N L} \mathbf{d}\right)=\mathbf{B}_{L} d(\mathbf{d})+d\left(\mathbf{B}_{N L}\right) \mathbf{d}+\mathbf{B}_{N L} d(\mathbf{d})=\mathbf{B}_{L} d(\mathbf{d})+2 \mathbf{B}_{N L} d(\mathbf{d})
$$

Or, expressed in rate form,

$$
d\left(\mathbf{B}^{\varepsilon} \mathbf{d}\right)=\mathbf{B}_{L} \dot{\mathbf{d}}+2 \mathbf{B}_{N L} \dot{\mathbf{d}}=\left(\mathbf{B}_{L}+2 \mathbf{B}_{N L}\right) \dot{\mathbf{d}}=\mathbf{B} \dot{\mathbf{d}}
$$

Using Eqns. (A1) to (A7), and Eqn. (17), then Eqn. (18) is derived as follows,

$$
\begin{aligned}
& d\left(\mathbf{M}_{\sigma} \mathbf{D}^{\prime}\left(\mathbf{T}_{\varepsilon} \mathbf{B}^{\varepsilon} \mathbf{d}-\mathbf{M}_{e} \mathbf{e}\right)\right)=d(\{f\}+\hat{\mathbf{D}} \mathbf{e}) \Rightarrow \\
& \mathbf{M}_{\sigma} \mathbf{D}^{\prime} \mathbf{T}_{\varepsilon} \mathbf{B} \dot{\mathbf{d}}-\mathbf{M}_{\sigma} \mathbf{D}^{\prime} \mathbf{M}_{e} \dot{\mathbf{e}}=\dot{\hat{\mathbf{D}} \mathbf{e}}+\hat{\mathbf{D}} \dot{\mathbf{e}} \Rightarrow(\because \dot{\hat{\mathbf{D}}}=0) \\
& \mathbf{M}_{\sigma} \mathbf{D}^{\prime} \mathbf{T}_{\varepsilon} \mathbf{B} \dot{\mathbf{d}}=\mathbf{M}_{\sigma} \mathbf{D}^{\prime} \mathbf{M}_{e} \dot{\mathbf{e}}+\hat{\mathbf{D}} \dot{\mathbf{e}}=\left(\mathbf{M}_{\sigma} \mathbf{D}^{\prime} \mathbf{M}_{e}+\hat{\mathbf{D}}\right) \dot{\mathbf{e}} \Rightarrow \\
& \dot{\mathbf{e}}=\left(\hat{\mathbf{D}}+\mathbf{M}_{\sigma} \mathbf{D}^{\prime} \mathbf{M}_{e}\right)^{-1} \mathbf{M}_{\sigma} \mathbf{D}^{\prime} \mathbf{T}_{\varepsilon} \mathbf{B} \dot{\mathbf{d}}
\end{aligned}
$$

(2) Derivation of Eqn. (23) from Eqns. (12) (13) and (18)

The first term on the right side of Eqn. (21) can be expressed as

$$
\int_{V} \mathbf{B}^{T} \dot{\boldsymbol{\sigma}} d V=\int_{V} \mathbf{B}^{T}\left(\mathbf{D} \dot{\widetilde{\boldsymbol{\varepsilon}}}_{x}\right) d V
$$

Substituting Eqn. (13) into the Eqn. (A9), then

$$
\int_{V} \mathbf{B}^{T} \dot{\boldsymbol{\sigma}} d V=\int_{V} \mathbf{B}^{T} \mathbf{D}\left(\dot{\boldsymbol{\varepsilon}}-\mathbf{T}_{\varepsilon}^{-1} \mathbf{M}_{e} \dot{\mathbf{e}}\right) d V
$$

Substitute Eqn. (12) into Eqn. (A10) and using Eqns. (A1) to (A7), one can be obtained as

$$
\int_{V} \mathbf{B}^{T} \dot{\boldsymbol{\sigma}} d V=\int_{V} \mathbf{B}^{T} \mathbf{D}\left(\mathbf{B} \dot{\mathbf{d}}-\mathbf{T}_{\varepsilon}^{-1} \mathbf{M}_{e} \dot{\mathbf{e}}\right) d V
$$

Finally, substitute Eqn. (18) into Eqn. (A11) the Eqn. (23) is derived as follows

$$
\begin{aligned}
& \int_{V} \mathbf{B}^{T} \dot{\boldsymbol{\sigma}} d V=\int_{V} \mathbf{B}^{T} \mathbf{D}\left(\mathbf{B} \dot{\mathbf{d}}-\mathbf{T}_{\varepsilon}^{-1} \mathbf{M}_{e}\left(\hat{\mathbf{D}}+\mathbf{M}_{\sigma} \mathbf{D}^{\prime} \mathbf{M}_{e}\right)^{-1} \mathbf{M}_{\sigma} \mathbf{D}^{\prime} \mathbf{T}_{\varepsilon} \mathbf{B} \dot{\mathbf{d}}\right) d V \Rightarrow \\
& \int_{V} \mathbf{B}^{T} \dot{\boldsymbol{\sigma}} d V=\int_{V} \mathbf{B}^{T} \mathbf{D}\left(\mathbf{I}-\mathbf{T}_{\varepsilon}^{-1} \mathbf{M}_{e}\left(\hat{\mathbf{D}}+\mathbf{M}_{\sigma} \mathbf{D}^{\prime} \mathbf{M}_{e}\right)^{-1} \mathbf{M}_{\sigma} \mathbf{D}^{\prime} \mathbf{T}_{\varepsilon}\right) \mathbf{B} \dot{\mathbf{d}} d V \Rightarrow \\
& \int_{V} \mathbf{B}^{T} \dot{\boldsymbol{\sigma}} d V=\left(\int_{V} \mathbf{B}^{T} \mathbf{D}\left(\mathbf{I}-\mathbf{T}_{\varepsilon}^{-1} \mathbf{M}_{e}\left(\hat{\mathbf{D}}+\mathbf{M}_{\sigma} \mathbf{D}^{\prime} \mathbf{M}_{e}\right)^{-1} \mathbf{M}_{\sigma} \mathbf{D}^{\prime} \mathbf{T}_{\varepsilon}\right) \mathbf{B} d V\right) \dot{\mathbf{d}}
\end{aligned}
$$




\section{REFERENCES}

[1] Bailey, C.G. and Toh, W.S., "Small-scale concrete slab tests at ambient and elevated temperatures", Engineering Structures, 29, (2007), pp2775-2791.

[2] Foster, S., "Tensile membrane action of reinforced concrete slabs at ambient and elevated temperatures", PhD thesis, Department of Civil and Structural Engineering, University of Sheffield, 2006.

[3] Foster, S.J. et al., "Experimental behaviour of concrete floor slabs at large displacement", Engineering Structures, 26, (2004), pp1231-1247.

[4] Huang, Z., Burgess, I.W. and Plank, R.J., "Modelling Membrane Action of Concrete Slabs in Composite Buildings in Fire. Part I: Theoretical Development", Journal of Structural Engineering, 129 (8), (2003), pp1093-1102.

[5] Huang, Z., Burgess, I.W. and Plank, R.J., "Modelling Membrane Action of Concrete Slabs in Composite Buildings in Fire. Part II: Validations", Journal of Structural Engineering, 129 (8), (2003), pp1103-1112.

[6] Gillie, M. et al., "Modelling of heated composite floor slabs with reference to Cardington experiments", Fire Safety Journal, 36, (2001) pp745-767.

[7] Lim, L. et al., "Numerical modelling of two-way reinforced concrete slabs in fire", Engineering Structures, 26,(2004) pp1081-1091.

[8] Zhang, Y.X., and Bradford, M.A., "Nonlinear analysis of moderately thick reinforced concrete slabs at elevated temperatures using a rectangular layered plate element with Timoshenko beam functions", Engineering Structures, 29, (2007), pp 2751-2761.

[9] Izzuddin, B.A., Tao, X.Y., and Elghazouli, A.Y., "Realistic Modelling of Composite and R/C Floor Slabs under Extreme Loading - Part I: Analytical Method", Journal of Structural Engineering, 130 (12), 2004, pp 1972-1984.

[10] Izzudin, B.A., and Elghazouli A.Y., "Failure of Lightly Reinforced Concrete Members under Fire. I: Analytical Modelling", Journal of Structural Engineering, 130(1), (2004), pp 3-17.

[11] Elghazouli A.Y., and Izzudin, B.A., "Failure of Lightly Reinforced Concrete Members under Fire. II: Parametric Studies and Design Considerations", Journal of Structural Engineering, 130(1), (2004), pp 18-31.

[12] Jirasek M., Belytschko T., "Computational resolution of strong discontinuities", $5^{\text {th }}$ World Congress on Computational Mechanics, Vienna, Austria. 2002. Eds.: H.A. Mang, F.G. Rammerstorfer, J. Eberhardsteiner.

[13] Fan S.C., Liu, X., and Lee, C.K., "Enriched partition-of-unity finite element method for stress intensity factors at crack tips", Computers and Structures, 82, (2004), pp. 445-461.

[14] Sukumar, N. and Prevost, J.H., "Modeling quasi-static crack growth with the extended finite element method Part I: Computer implementation", International Journal of Solids and Structures, 40, (2003), pp.7513-7537.

[15] Areias, P.M.A. and Belytschko, T., "Non-linear analysis of shells with arbitrary evolving cracks using XFEM", Int. J. Numerical Methods in Engineering, 62, (2005), pp.384-415.

[16] Bazant, Z.P. and Oh, B.H., "Crack band theory for fracture of concrete", Material and Structures, 16, (1983), pp155-177.

[17] Bazant, Z.P., "Scaling theory for quasibrittle structural failure", PNAS (The National Academy of Sciences of USA), 101, (2004), pp 13400-13407.

[18] Bathe, Klaus-Jürgen, "Finite element procedures", Prentice-Hall, New Jersey, (1996). 
[19] Jirasek, M. and Zimmermann, T., "Embedded crack model: I. Basic formulation", Int. J. Numerical Methods in Engineering, 50, (2001), pp1269-1290.

[20] Wells, G.N. and Sluys, J., "Three-dimensional embedded discontinuity model for brittle fracture", International Journal of Solids and Structures, 38, (2001), pp.897-913.

[21] CEB-FIP Model Code: Comite Euro-International du Beton, Bulletin D'information No. 213/214, Tomas Telford, London, May 1993.

[22] Bazant, Z.P. and Becq-Giraudon, E., "Statistical prediction of fracture parameters of concrete and implications for choice of testing standard", Cement and Concrete Research, 32, (2002), pp529-556.

[23] Yamamoto, T. and Vecchio, F., "Analysis of reinforced concrete shells for transverse shear and torsion", ACI Structural Journal, 98, (2001), pp 191-200. 
TABLES

Table 1. Details of test slabs at ambient temperature [1].

\begin{tabular}{|l|c|c|c|c|}
\hline \multicolumn{1}{|c|}{ Test specimen } & M1 & M2 & $M 3$ & $M 4$ \\
\hline Size $(\mathrm{m})$ & $1.8 \times 1.2$ & $1.2 \times 1.2$ & $1.8 \times 1.2$ & $1.2 \times 1.2$ \\
\hline Size in support $(\mathrm{m})$ & $1.7 \times 1.1$ & $1.1 \times 1.1$ & $1.7 \times 1.1$ & $1.1 \times 1.1$ \\
\hline Thickness $(\mathrm{mm})$ & 18.2 & 19.1 & 22.0 & 20.1 \\
\hline Diameter of steel bar $(\mathrm{mm})$ & 2.42 & 2.42 & 1.53 & 1.53 \\
\hline Spacing of steel bar $(\mathrm{mm})$ & 50.8 & 50.8 & 25.4 & 25.4 \\
\hline Yield strength of steel $f_{y}(\mathrm{MPa})$ & 732 & 732 & 451 & 451 \\
\hline Concrete strength $f_{c u}(\mathrm{MPa})$ & 41.3 & 38 & 35.3 & 35.3 \\
\hline Concrete cover $(\mathrm{mm})$ & 5 & 5 & 5 & 5 \\
\hline Water-cement ratio & 0.3 & 0.3 & 0.3 & 0.3 \\
\hline Maximum aggregate size $(\mathrm{mm})$ & 6 & 6 & 6 & 6 \\
\hline Yield line load $\left(\mathrm{kN} / \mathrm{m}^{2}\right)$ & 8.52 & 13.80 & 6.35 & 8.17 \\
\hline
\end{tabular}

Table 2. Details of test slabs at elevated temperatures $[1,2]$.

\begin{tabular}{|l|c|c|c|}
\hline \multicolumn{1}{|c|}{ Test specimen } & FT10 [2] & FT20 [2] & MF1[1] \\
\hline Size $(\mathrm{mm})$ & $920 \times 620$ & $920 \times 620$ & $1800 \times 1200$ \\
\hline Size in support (mm) & $850 \times 550$ & $850 \times 550$ & $1700 \times 1100$ \\
\hline Thickness $(\mathrm{mm})$ & 24 & 26 & 19.7 \\
\hline Diameter of steel bar (mm) & 0.71 & 0.71 & 2.43 \\
\hline Spacing of steel bar (mm) & & & 50.8 \\
\hline Yield strength of steel $f_{y}(\mathrm{MPa})$ & 250 & 250 & 722 \\
\hline Concrete strength $f_{c u}(\mathrm{MPa})$ & 39 & 40 & 43.2 \\
\hline Concrete cover $(\mathrm{mm})$ & 7.5 & 7.5 & 5 \\
\hline Water-cement ratio & 0.47 & 0.47 & 0.3 \\
\hline Maximum aggregate size $(\mathrm{mm})(\mathrm{mm})$ & 4 & 4 & 6 \\
\hline Yield line load $\left(\mathrm{kN} / \mathrm{m}^{2}\right)$ & 2.49 & 5.17 & 9.52 \\
\hline
\end{tabular}




\section{FIGURE CAPTIONS}

Fig. 1 Division of reinforced concrete slabs into plate elements.

Fig. 2 Individual crack is decomposed into independent virtual sub-cracks at integration points within the element.

Fig. 3 Effective length $l_{\text {eff }}^{n}$ of an element with a crack band in $n$-direction.

Fig. 4 Linear and bi-linear tensile softening curves of concrete.

Fig. 5 Comparison of predicted and measured central deflections of Slab-M1 [1] using different meshes.

Fig. 6 Comparison of predicted and measured central deflections of Slab-M2 [1] using different meshes.

Fig. 7 Comparison of predicted and measured central deflections of Slab-M3 [1] using different meshes.

Fig. 8 Comparison of predicted and measured central deflections of Slab-M4 [1].

Fig. 9 Integration positions in an element adjacent to the centre of the slab.

Fig. 10 Comparison of predicted reinforcement stresses at the integration point closest to the centre of Slab-M1 [1] using different FE meshes.

Fig. 11 Predicted cracking pattern of the bottom layer of the Slab-M1 at the load of $20 \mathrm{kN} / \mathrm{m}^{2}$ (all units in $\mathrm{mm}$ ).

Fig. 12 Predicted cracking pattern of the top layer of the Slab-M1 at the load of $20 \mathrm{kN} / \mathrm{m}^{2}$ (all units in $\mathrm{mm}$ ).

Fig. 13 Crack opening through the thickness of Slab-M1 at central position (Element\#15) at the load of $20 \mathrm{kN} / \mathrm{m}^{2}$ (all units in $\mathrm{mm}$ ).

Fig. 14 Tested cracking pattern of the top surface of the Slab-M1 [1].

Fig. 15 Comparison of predicted and measured central deflections of Slab - FT10 [2]

Fig. 16 Comparison of predicted and measured central deflections of Slab-FT20 [2].

Fig. 17 Comparison of predicted and measured central deflections of Slab-MF1 [1].

Fig. 18 Predicted cracking pattern of the bottom layer of the Slab-MF1 at $800{ }^{\circ} \mathrm{C}$ of reinforcement temperature (all units in $\mathrm{mm}$ ). 
Fig. 19 Tested cracking pattern of the top surface of the Slab-MF1 [1]. 


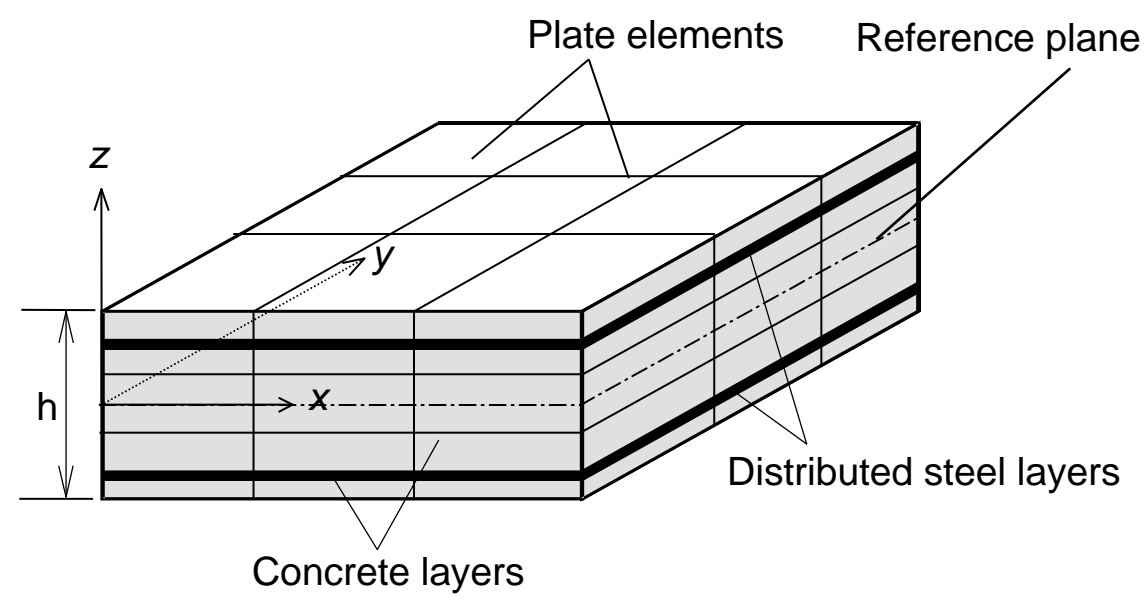

Fig. 1

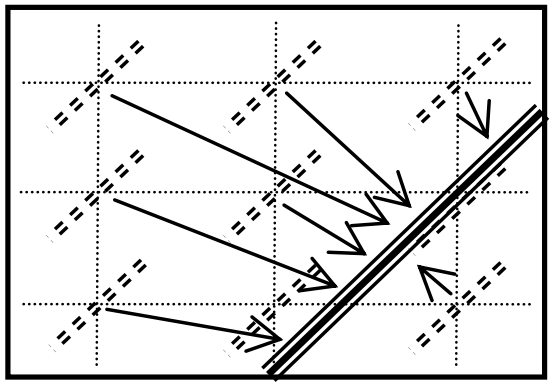

Fig. 2 


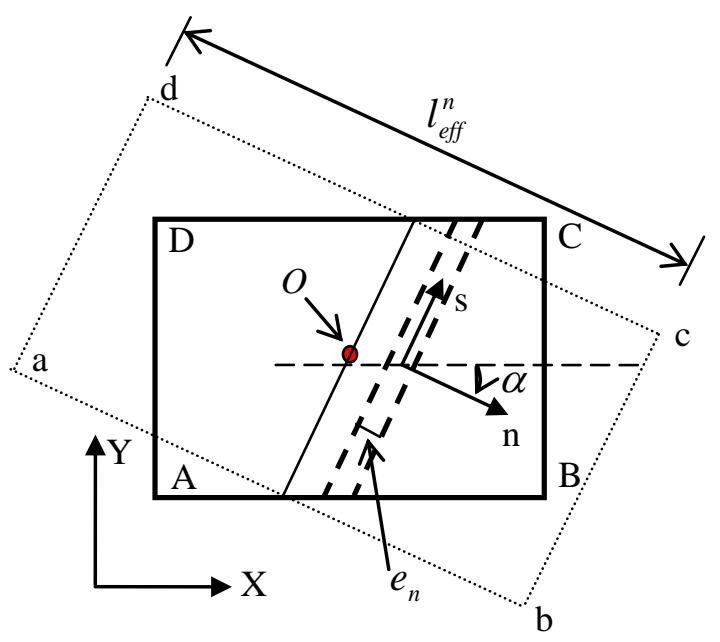

Fig. 3

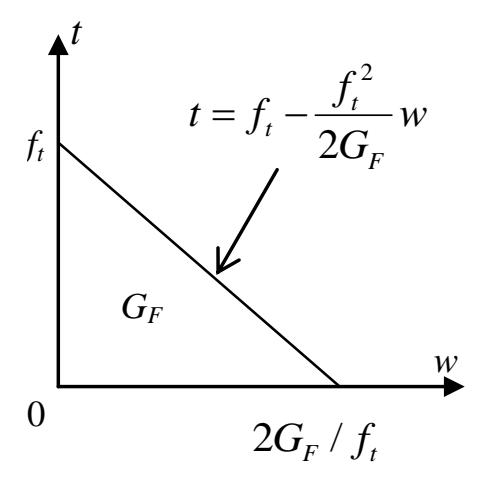

Linear Softening Curve

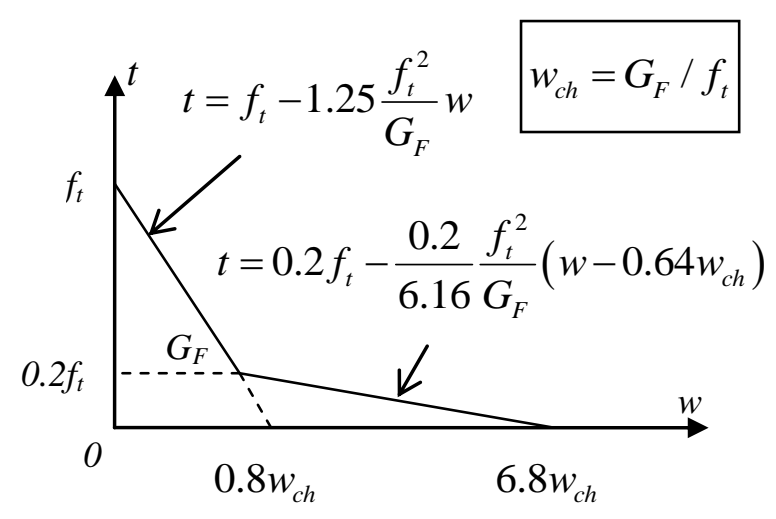

Bi-Linear Softening Curve

Fig. 4 
Central Deflection (mm)

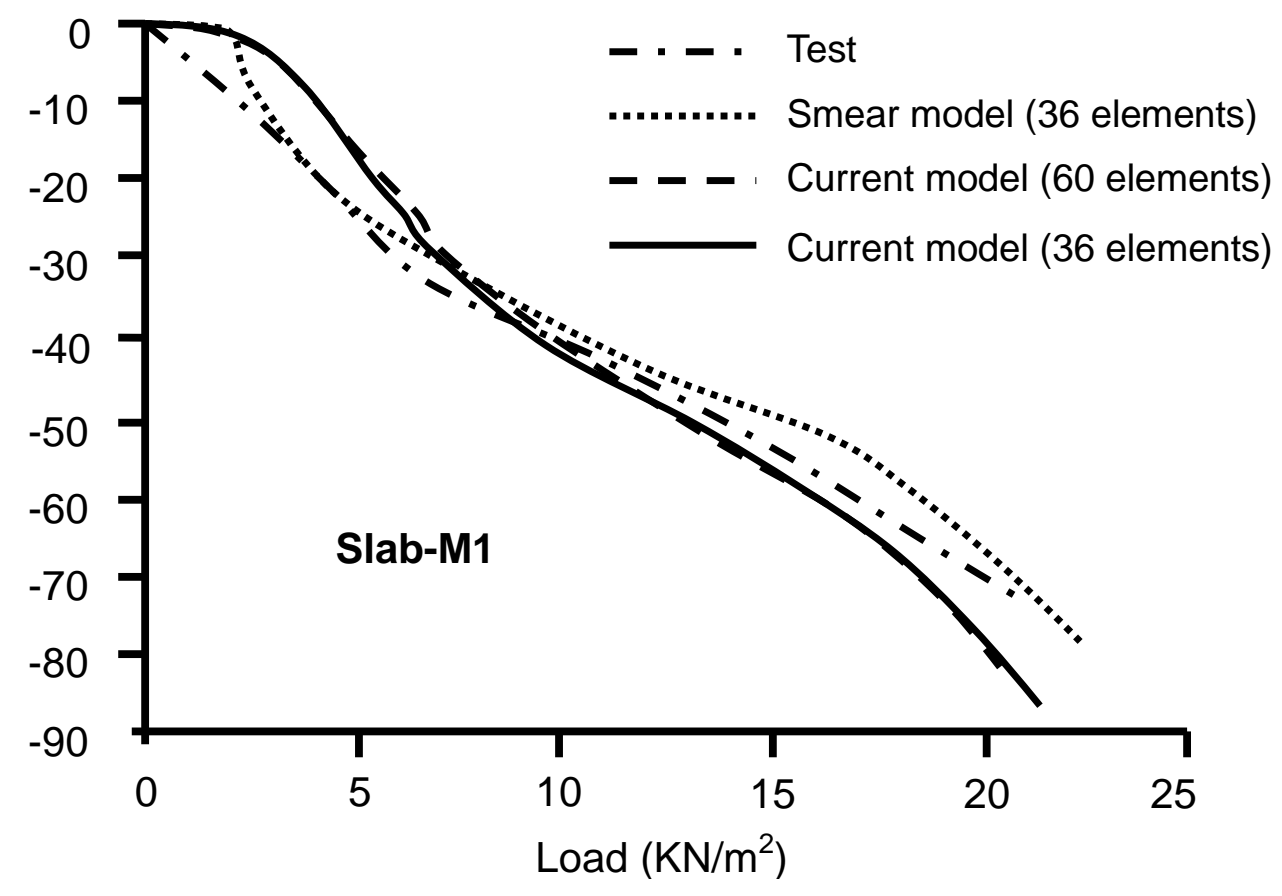

Fig. 5

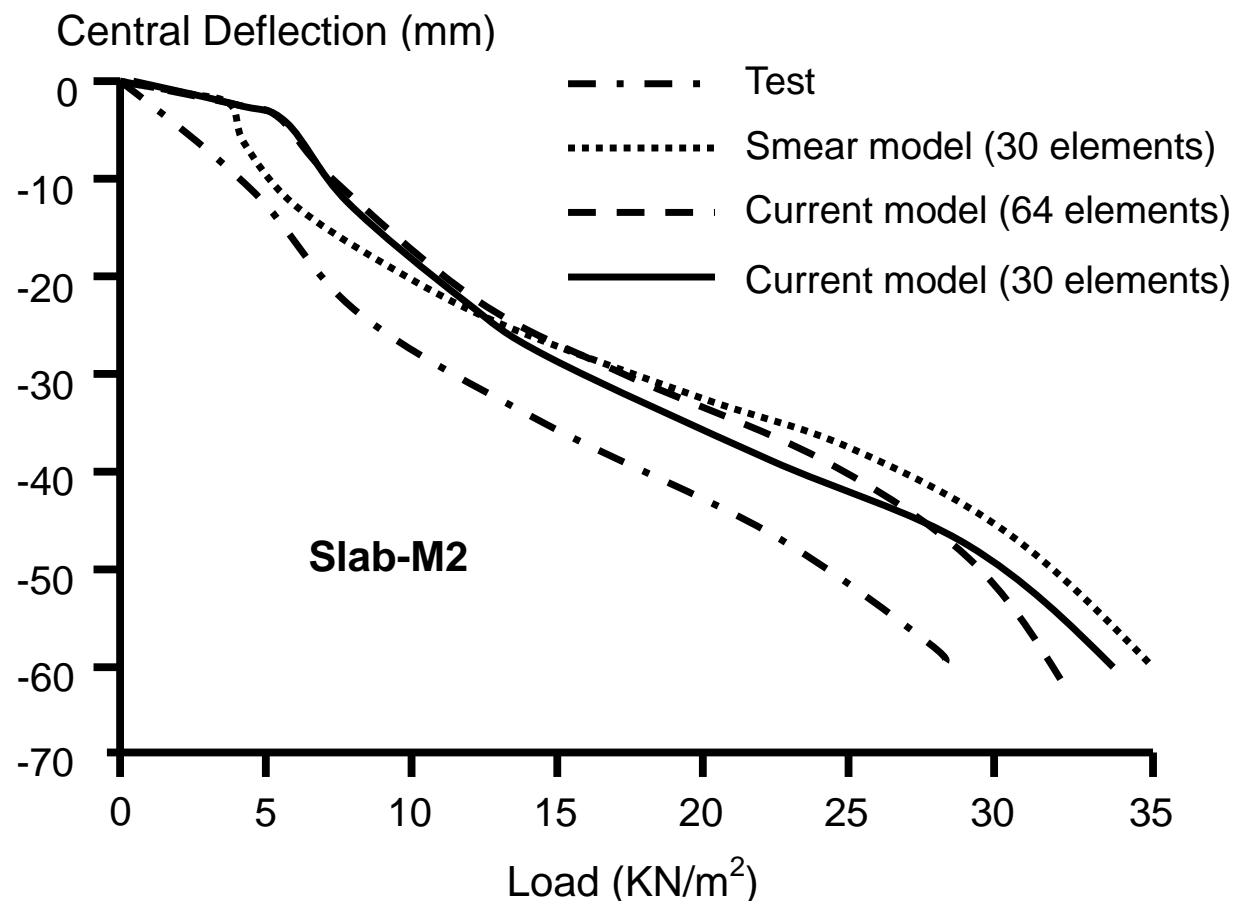

Fig. 6 


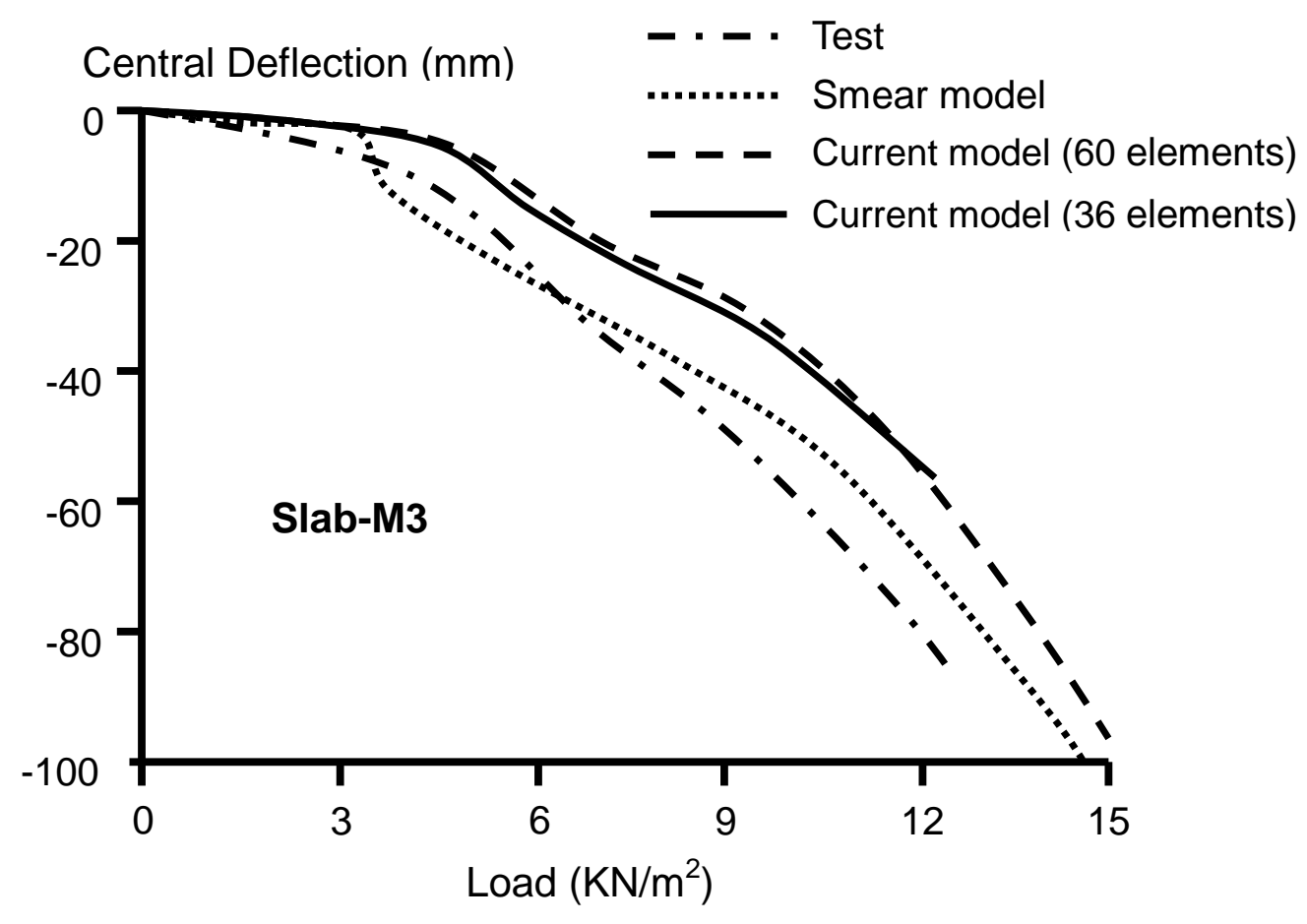

Fig. 7

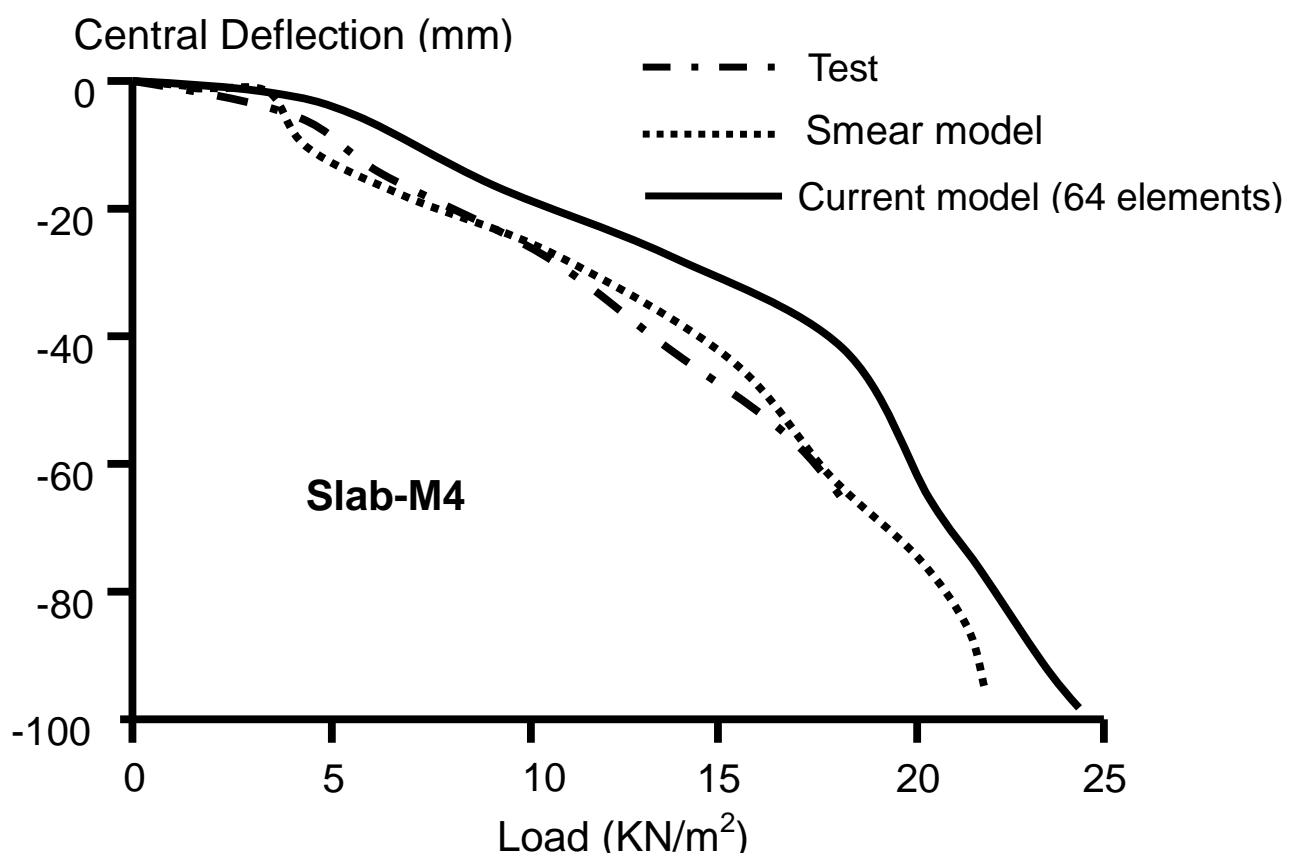

Fig. 8 


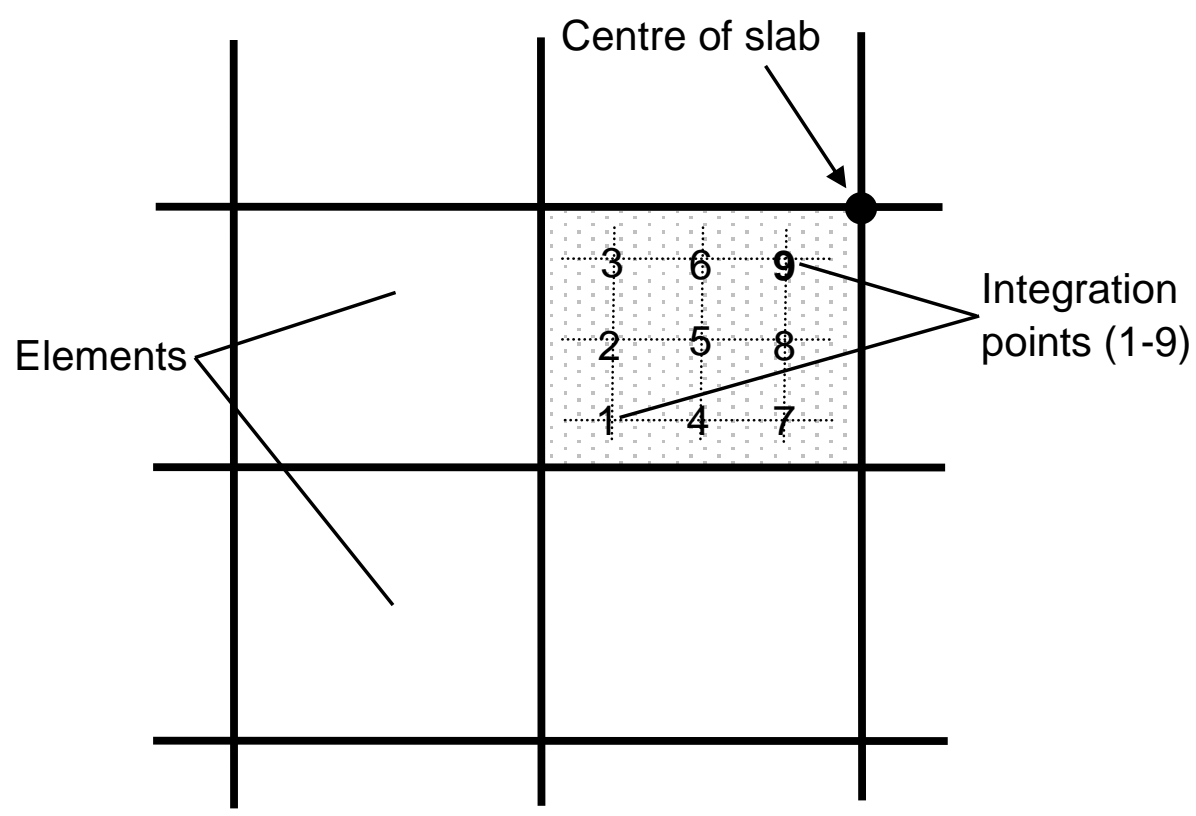

Fig. 9

Reinforcement Stress (MPa)

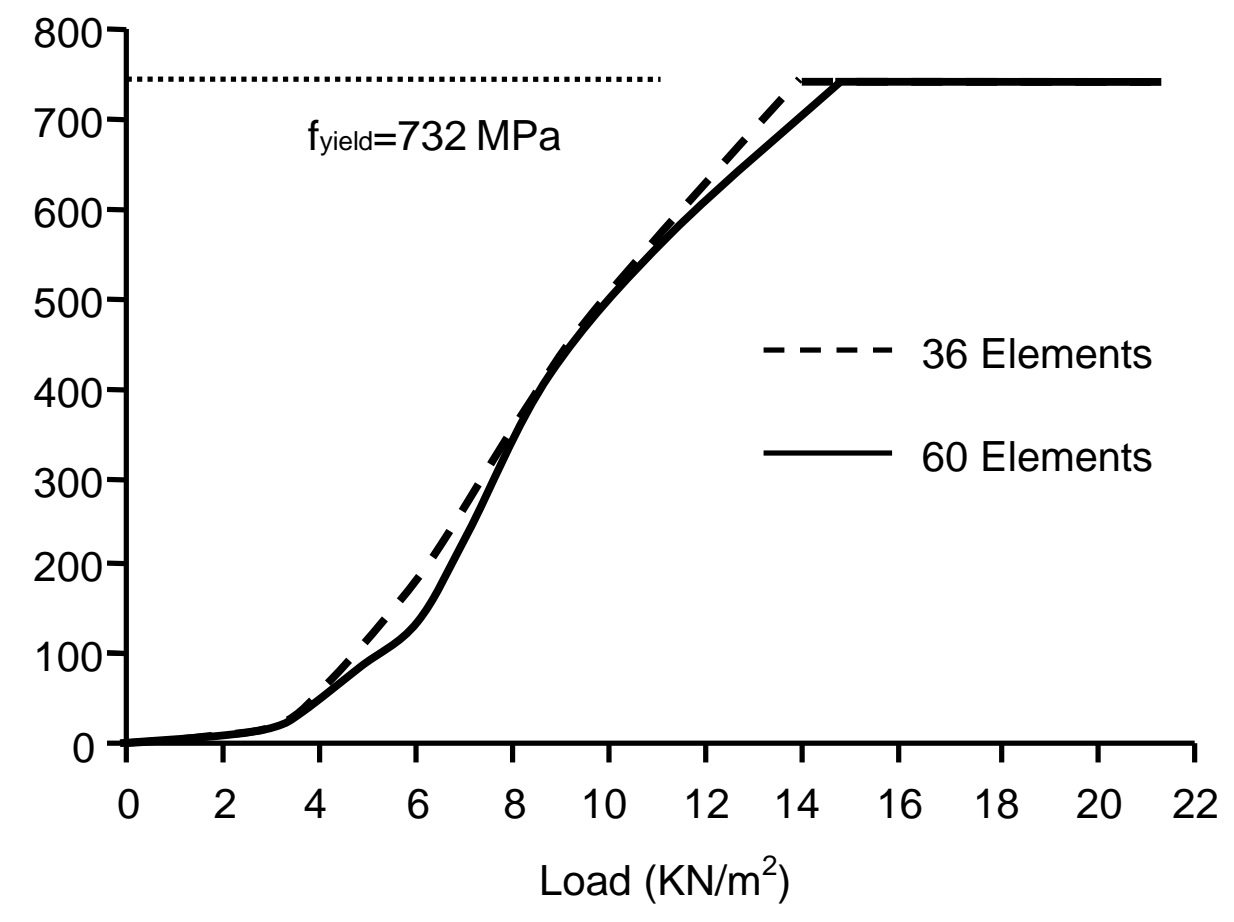

Fig. 10 


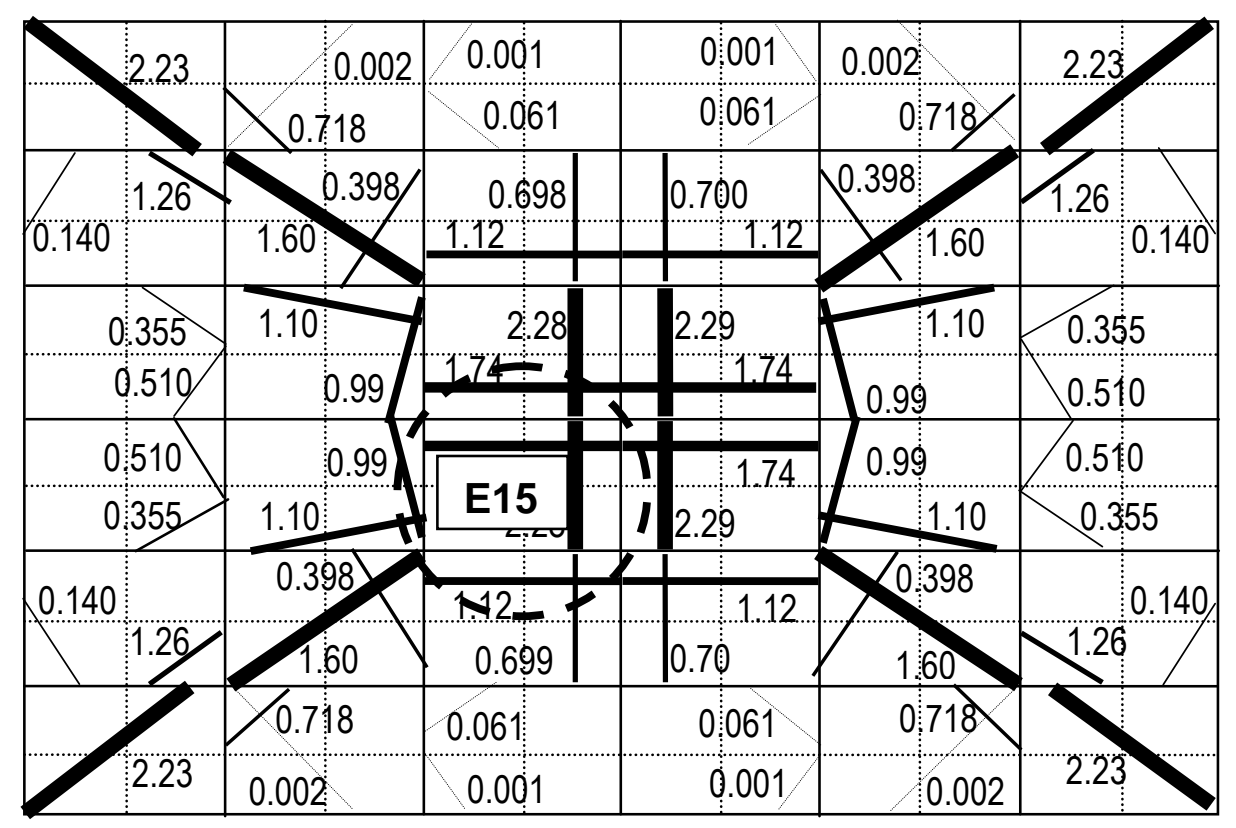

Fig. 11

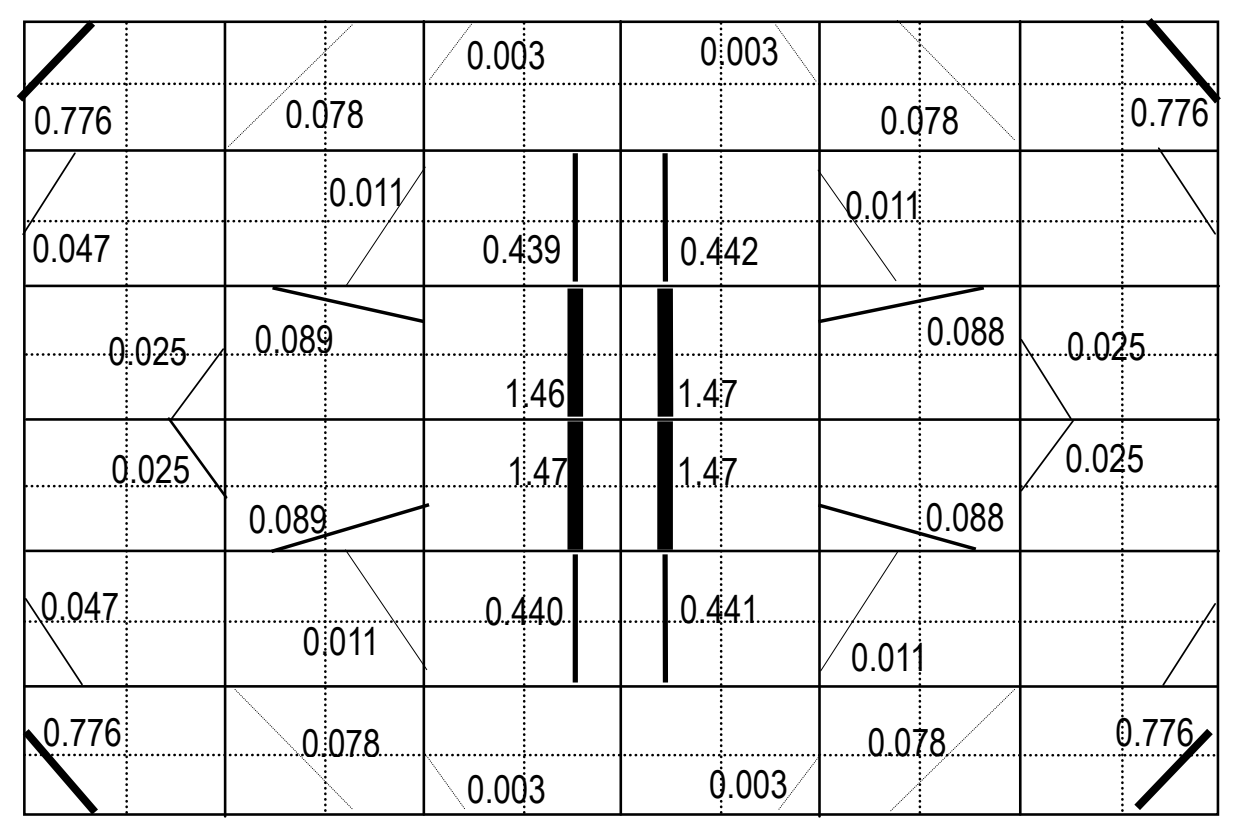

Fig. 12 


\begin{tabular}{|c|c|c|c|}
\hline \\
\hline \multicolumn{4}{|c|}{ 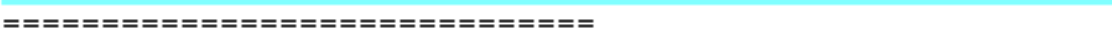 } \\
\hline \multicolumn{4}{|c|}{$\begin{array}{l}\text { iteration\# } \quad 0 \\
==1\end{array}$} \\
\hline \multicolumn{4}{|c|}{$\begin{array}{l}\text { Cracked Embedded Elements in } \\
\text { Ele\#: } 15 \mathrm{GPs} 9 \mathrm{~g} \text { nir (C) }\end{array}$} \\
\hline L: 1 Enhance= & $.174 \mathrm{E}+01$ & $.228 \mathrm{E}+01$ & \\
\hline Enhance $=$ & $.162 \mathrm{E}+01$ & $.223 \mathrm{E}+01$ & \\
\hline Enhance $=$ & $.150 \mathrm{E}+01$ & .219501 & not cracked. \\
\hline Enhance= & $.139 \mathrm{E}+01$ & $214 E+01$ & \\
\hline Enhance= & $.127 \mathrm{E}+01$ & $.209 E+01$ & \\
\hline Enhance $=$ & $.119 \mathrm{E}+01$ & $.206 \mathrm{E}+01$ & Reintorcement \\
\hline Enhance $=$ & $.112 \mathrm{E}+01$ & $.203 \mathrm{E}+01$ & lavers \\
\hline Enhance $=$ & $.104 \mathrm{E}+01$ & $.199 \mathrm{E}+01$ & \\
\hline Enhance $=$ & $.923 \mathrm{E}+00$ & $.195 \mathrm{E}+01$ & \\
\hline Enhance= & $.801 \mathrm{E}+00$ & $.189 \mathrm{E}+01$ & \\
\hline Enhance= & $.644 \mathrm{E}+00$ & $.183 \mathrm{E}+01$ & \\
\hline Enhance $=$ & $.434 \mathrm{E}+00$ & $.174 \mathrm{E}+01$ & \\
\hline Enhance $=$ & $.196 \mathrm{E}+00$ & $.165 \mathrm{E}+01$ & cracked. \\
\hline Enhance $=$ & $.131 \mathrm{~F}-01$ & $.155 \mathrm{E}+01$ & \\
\hline Enhance $=$ & $.000 \mathrm{E}+00 \mathrm{D}$ & $.147 \mathrm{E}+01 \mathrm{D}$ & \\
\hline Ele\#: $16 \mathrm{GPs}$ & 33 NDIr $(C)$ & $: 89.820$ & lop layer \\
\hline L: $1 \quad$ Enhance= & $.174 \mathrm{E}+01$ & $.229 \mathrm{E}+01$ & \\
\hline Enhance $=$ & $.162 \mathrm{E}+01$ & $.224 E+01$ & \\
\hline & $\begin{array}{l}\text { Crack in long } \\
\text { span directoin }\end{array}$ & $\begin{array}{l}\text { Crack in short } \\
\text { span directoin }\end{array}$ & \\
\hline
\end{tabular}

Fig. 13

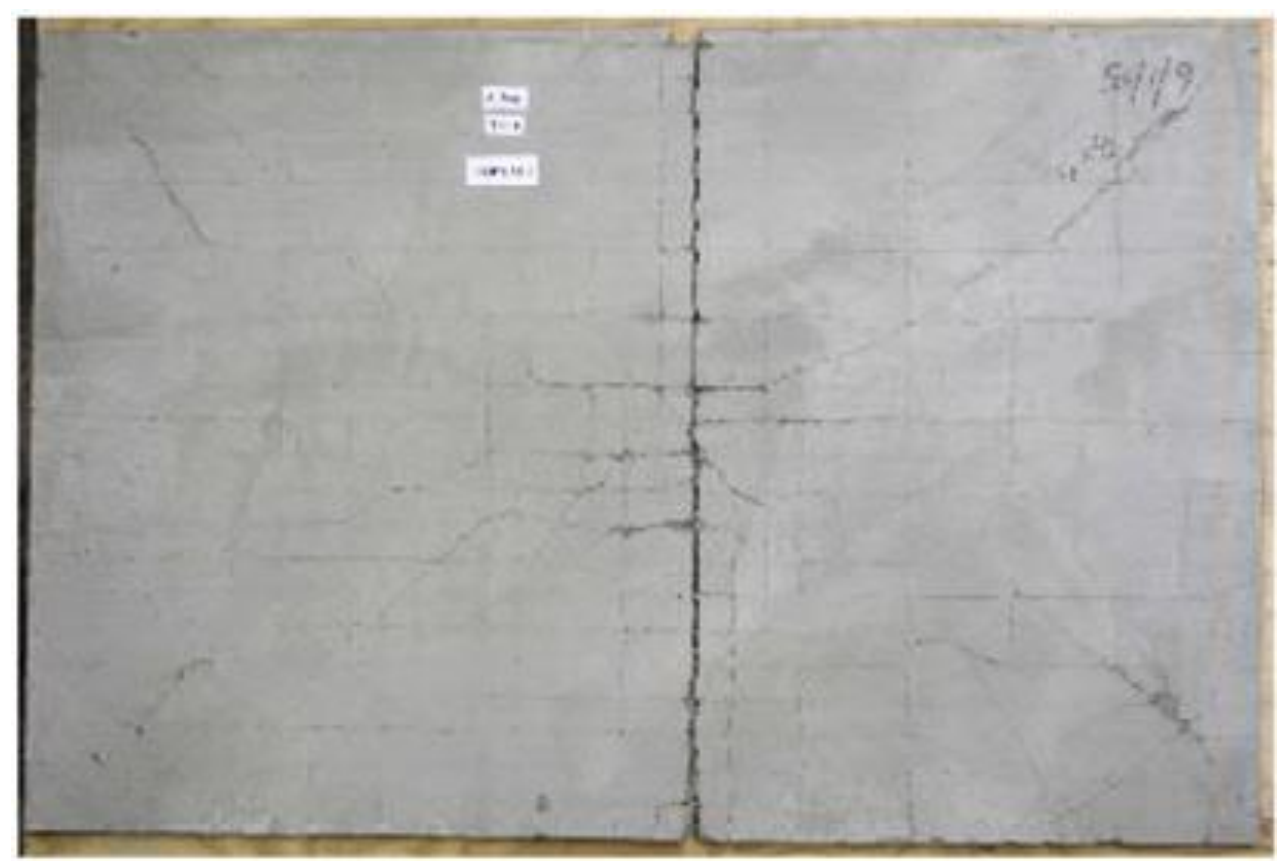

Fig. 14 


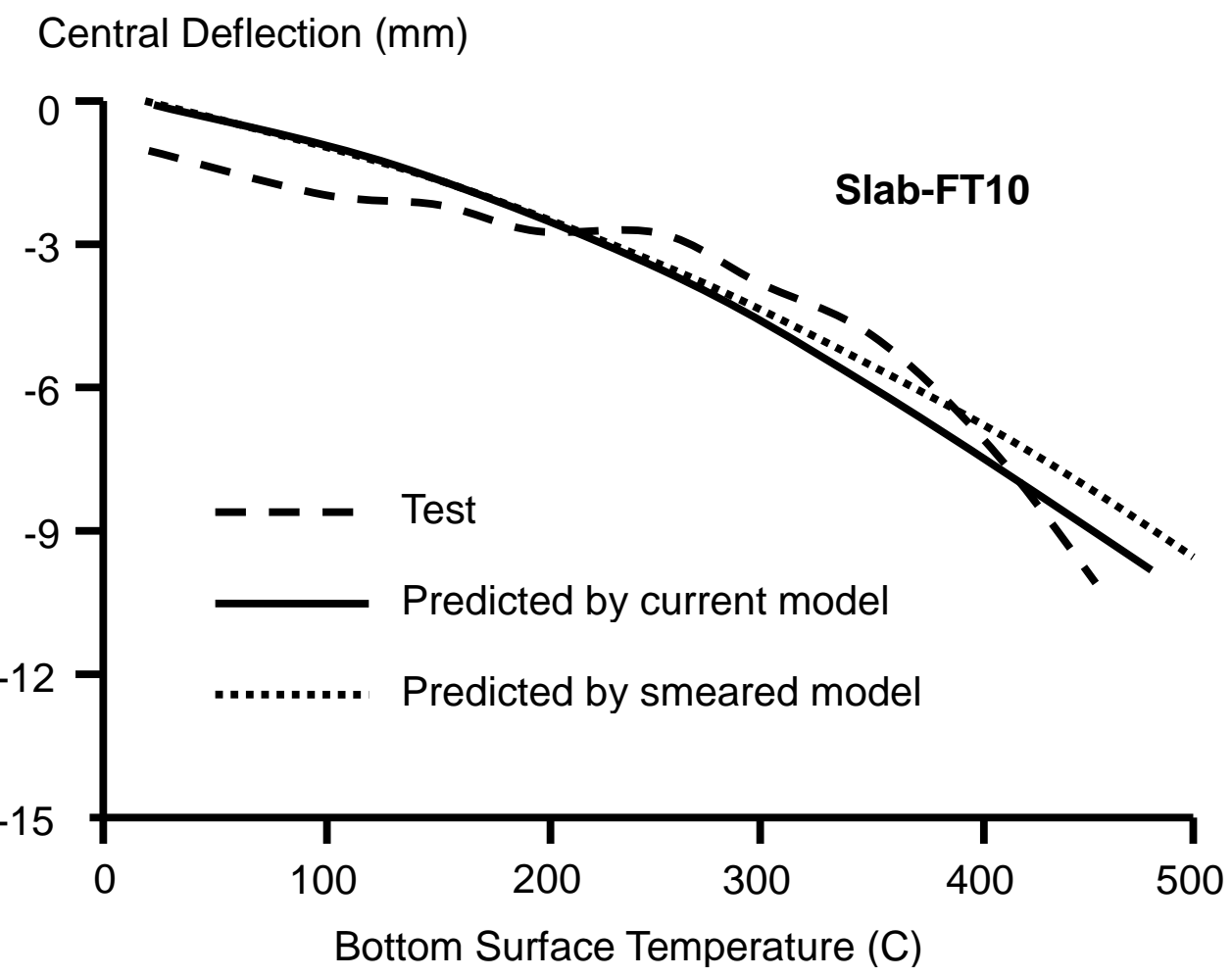

Fig. 15

Central Deflection (mm)

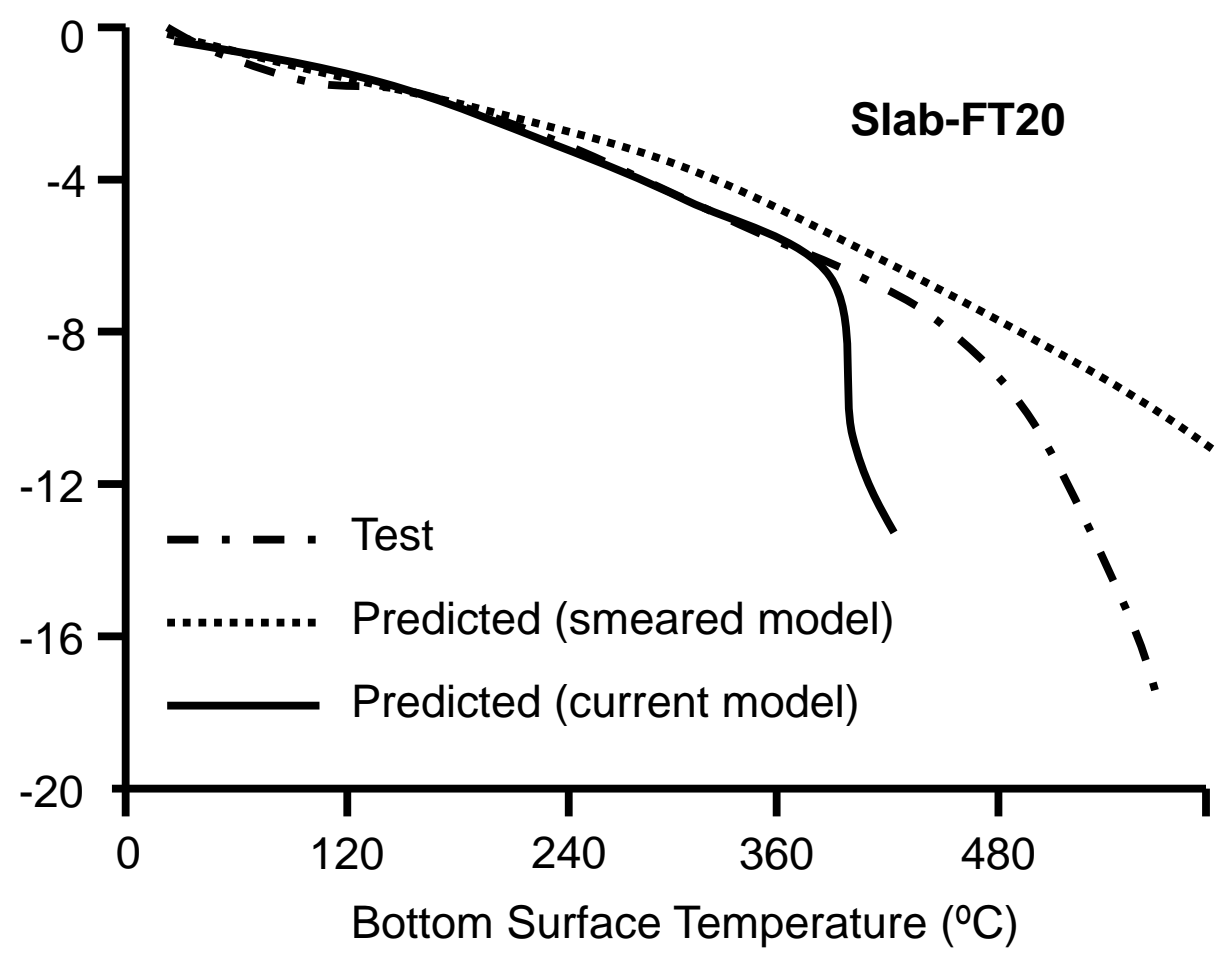

Fig. 16 


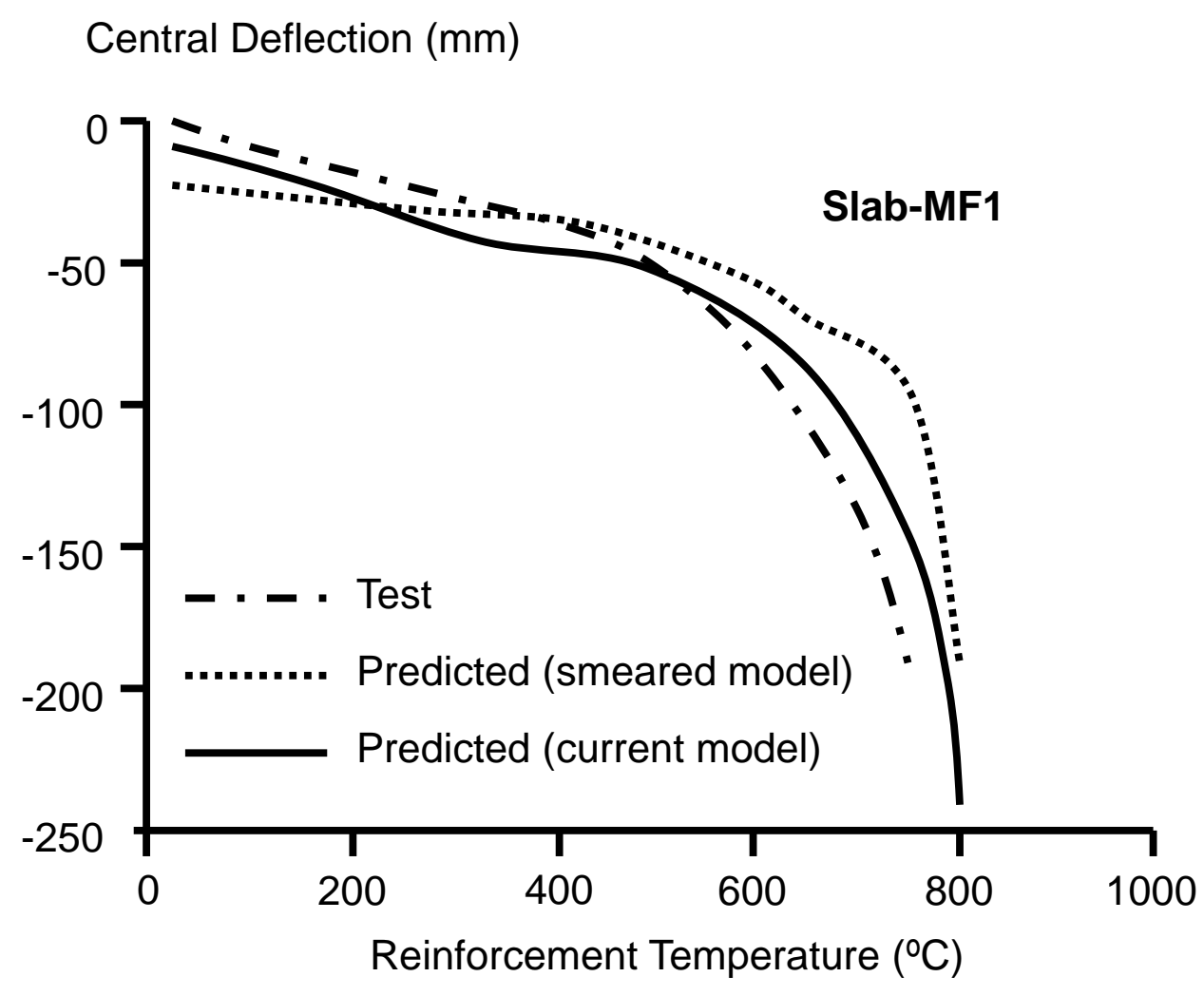

Fig. 17

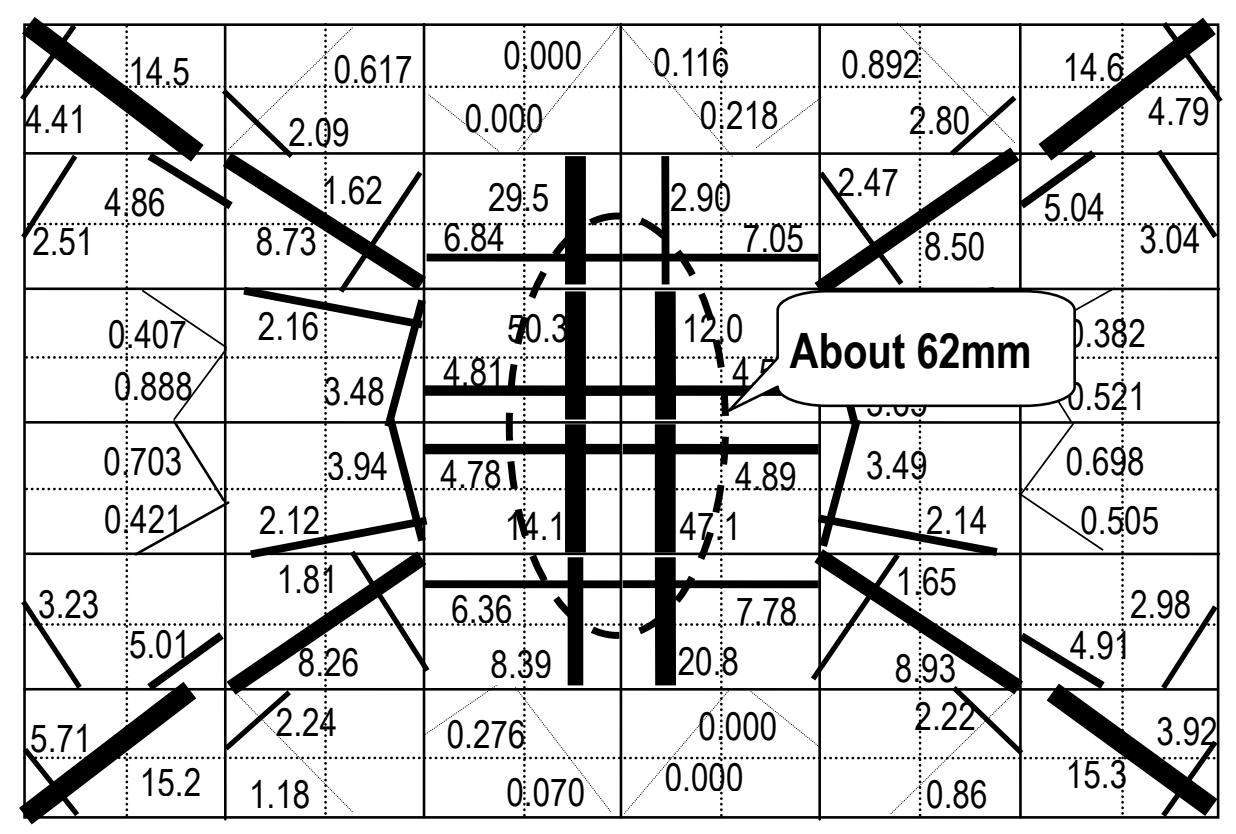

Fig. 18 


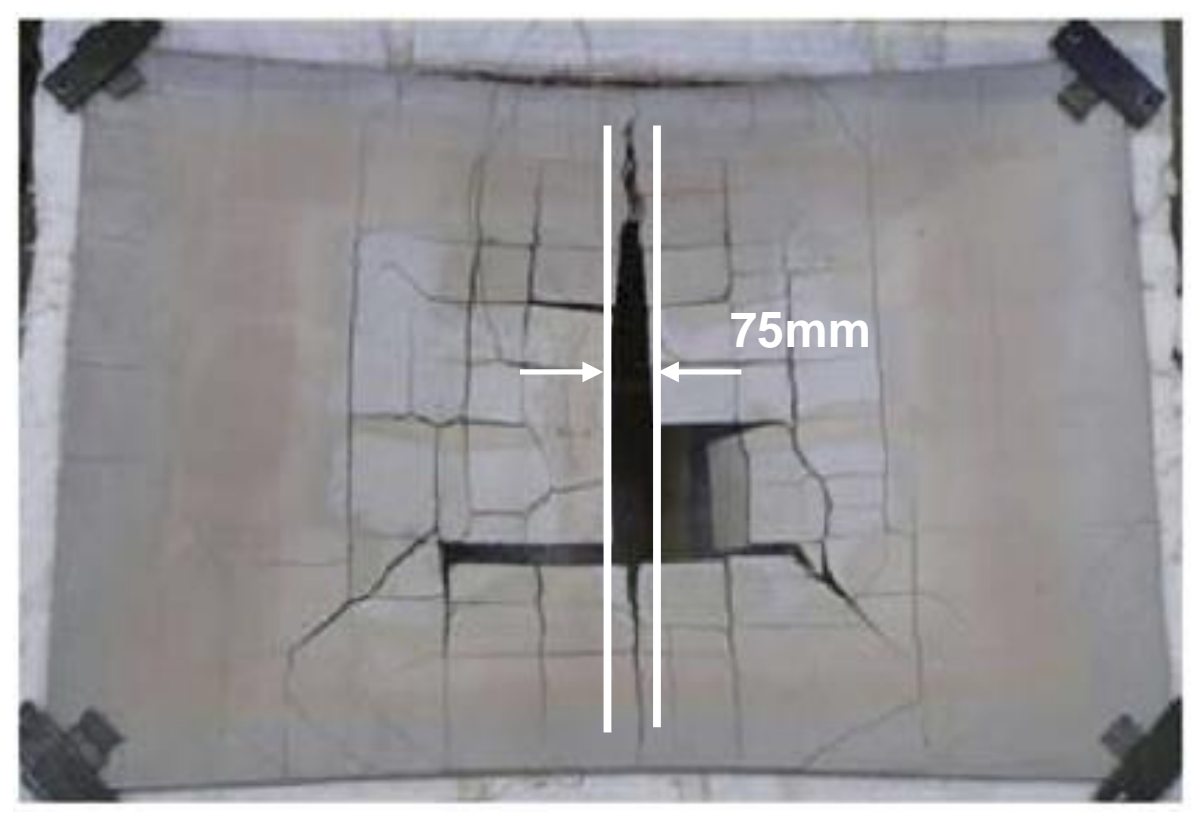

Fig. 19 